Portland State University

PDXScholar

1979

\title{
An investigation of the consistency of stimulus overselection of autistic children
}

Patricia O'Meara Walker

Portland State University

Follow this and additional works at: https://pdxscholar.library.pdx.edu/open_access_etds

Part of the Cognition and Perception Commons, and the Speech Pathology and Audiology Commons Let us know how access to this document benefits you.

\section{Recommended Citation}

Walker, Patricia O'Meara, "An investigation of the consistency of stimulus overselection of autistic children" (1979). Dissertations and Theses. Paper 2909.

https://doi.org/10.15760/etd.2906

This Thesis is brought to you for free and open access. It has been accepted for inclusion in Dissertations and Theses by an authorized administrator of PDXScholar. Please contact us if we can make this document more accessible: pdxscholar@pdx.edu. 
AN ABSTRACT OF THE THESIS OF Patricia O'Meara Walker for the Master of Science in Speech Communication: emphasis in Speech Pathology and Audiology presented May 4, 1979.

Title: An Investigation of the Consistency of Stimulus Overselection of Autistic Children.

APPROVED BY MEMBERS OF THE THESIS COMMITTEE:

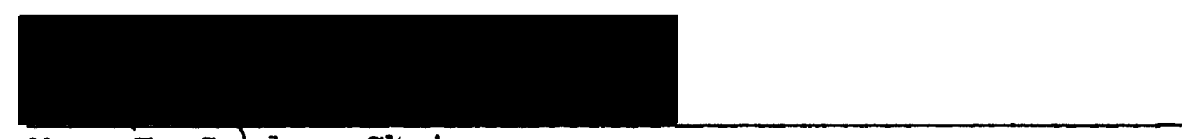

Mary E. Gefdon, Chairperson

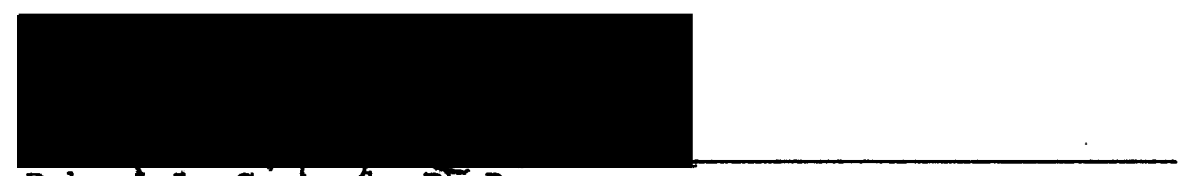

Robert L. Casteel, Ph.D.

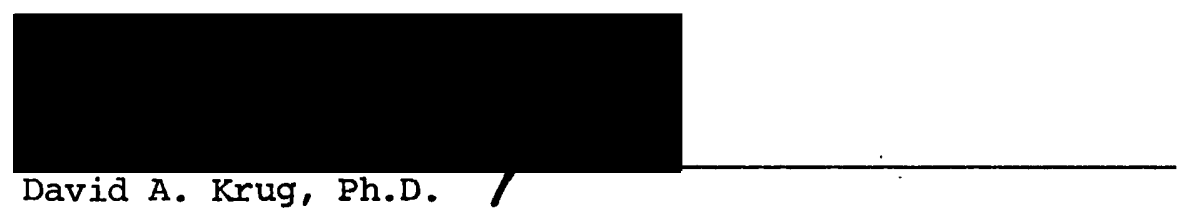

A review of the literature indicated that not all of the research in the area of overselectivity of autistic children has been in agreement. It does seem evident that some autistic children overselect. This could be the result of an attentional factor or a modality preference. This has important implications for the education of autistic children. In the light of the inconsistency of autistic children's reactions to sensory stimuli (Hermelin and O'Connor, 1970; Wing, 1972; Koegel, 1976) this investigator believed there was a need to determine 
if overselection is consistent before referring to the overselected modality as a preferred modality or comparing overselected modalities with the child's mode of communication (manual or speech).

This investigation constituted a replication of the methodology of $\mathrm{Krug}$ et al. (1978). The major difference in this investigation was it was conducted on two days for:comparison of results over time. The study by Krug et al. was conducted on one day. In this investigation no comparison was made with the child's mode of communication.

The questions posed by this study were:

1. Does an autistic child consistently exhibit overselection or the absence of overselection two times over a period of seven days, as indicated by measuring the latency of response to the different stimulus modalities?

2. Does an autistic child overselect the same modality, two times over a period of seven days, as indicated by measuring the latency of response to the different stimulus modalities?

To answer these questions, the reaction times of eight autistic subjects to various stimulus conditions were measured. Each child progressed through the following experimental sequence on two test days, four to seven days apart:

1. No stimulus condition

2. Auditory plus visual condition

3. Auditory or visual stimulus condition

4. Visual or auditory stimulus condition

5. Auditory plus visual condition

6. No stimulus condition

The reaction times to the auditory stimulus were compared with the reaction times to the visual stimulus for each test day. By comparing the number of reaction times slower than the mean, the modalities responded to faster were determined. This was considered 
to be the overselected modality. These results were compared for each child individually for the two test days to determine if the phenomenon of overselection was consistent over time.

In answer to question one, the data indicated four subjects were consistent in that they did not overselect on either test day. Three were inconsistent in that they indicated an overselection on only one of the two test days. Question two could not be answered by this investigation since no subject overselected on both test days. The results of this investigation do not support the concept of a preferred modality for autistic children as indicated by their overselection. They are consonant with Lovass' (1977; Lovass et al., 1971) explanation of overselection as attributable to an attentional factor. The child may simply attend to a modality on one day and not another. These results are not surprising considering the general inconsistency of reaction to sensory stimuli as noted by Hermelin and O'Connor (1970), Wing (1972) and Koegel (1976). This investigator believes it may be premature to implement teaching procedures through one particular overselected modality unless that modality has been consistently overselected over time by the individual child in question. 
AN INVESTIGATION OF THE CONSISTENCY OF STIMULUS OVERSELECTION OF AUTISTIC CHILDREN

\author{
by \\ PATRICIA O'MEARA WALKER
}

A thesis submitted in partial fulfillment of the requirements for the degree of

\begin{abstract}
MASTER OF SCIENCE IN SPEECH COMMUNICATION
with an emphasis in SPEECH PATHOLOGY/AUDIOLOGY
\end{abstract}

Portland State University 
TO THE OFFICE OF GRADUATE STUDIES AND RESEARCH:

The members of the Committee approve the thesis of Patricia O'Meara Walker presented May 4, 1979.

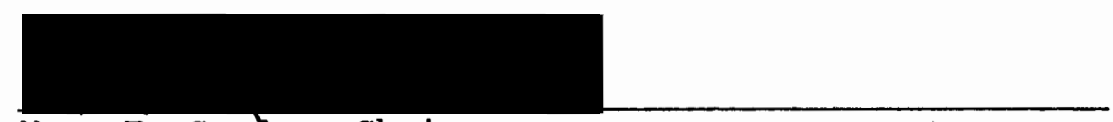

Mary E. Gorglon, Chairperson

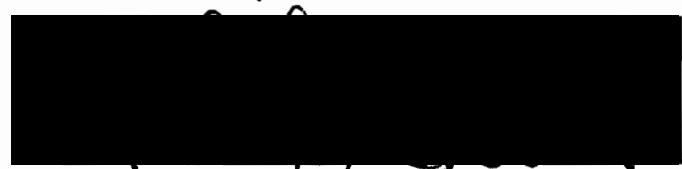

Robert L. Cagteel, Ph.D.

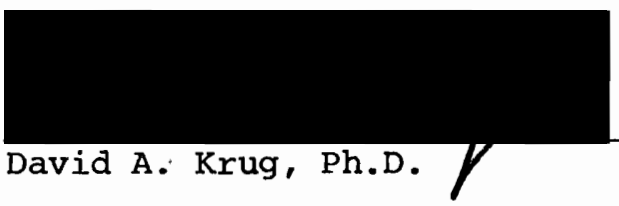

APPROVED :

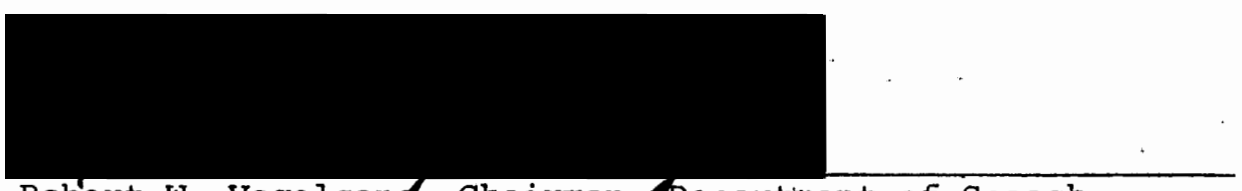

Robert w. Vogelsand, Chairman/Department of Speech

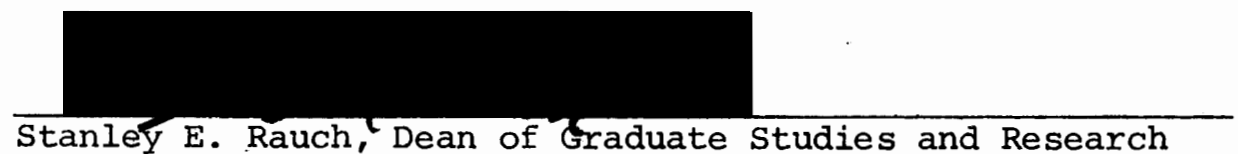




\section{ACKNOWLEDGEMENTS}

Many people were helpful in this endeavor. In particular, I want to thank the members of my graduate research committee, Robert Casteel, David Krug and Sheldon Maron for all their assistance and support. In addition, I am grateful to Ted Grove for his statistical assistance.

David Krug, Joel Arick, Pat Almond and the rest of the staff at the Autistic Education Program in Portland, Oregon deserve special recognition. My frequent interactions with this group were always positive and rewarding. Their continuing search for improvements in education for autistic children is inspirational.

The parents of the children who participated in this study deserve special recognition. They are very willing to cooperate in research efforts with their children.

I want to thank Rhoda Agin of California State University at Hayward for introducing me to the field of speech/language pathology; my parents for always supporting my efforts; Janice Simons for still being my friend; and my husband, Thom, for the mechanical operations on the apparatus used in this study, hours of mathematical calculation, and most of all for always being so supportive of me and my endeavors. Most of all, I sincerely thank Mary Gordon. It was a pleasure and privilege having her direct my thesis. She is an excellent model for anyone aspiring to be a speech/language pathologist. 
TABLE OF CONTENTS

PAGE

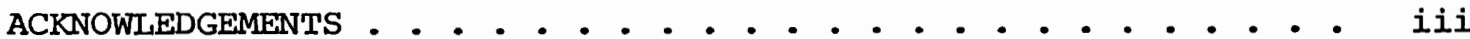

LIST OF TABLES . . . . . . . . . . . . . . . . . . . vi vi v v

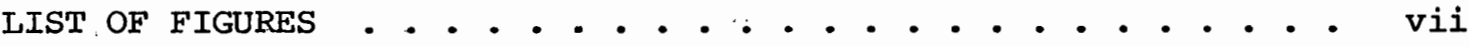

CHAPTER

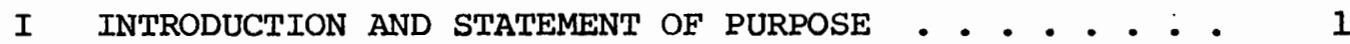

Introduction . . . . . . . . . . . . . 1

Statement of Purpose ............. 3

Definition of Terms ............. 4

II REVIEW OF THE IITERATURE . . . . . . . . . . . 5

Studies of Overselection of Autistic Children . . 5

Mode of Communication of Autistic Children . . . 10

Psycholinguistic Studies with Autistic Children . 12

Summary •. •. . . . . . . . . . . . 14

III METHODS AND PROCEDURES ................ 16

Subjects . . . . . . . . . . . . . 16

Instrumentation . . . . . . . . . . 16

Experimental Procedures .. . . . . . . 17

Data Measurement and Analysis . . . . . . 19

IV RESULTS AND DISCUSSION . . . . . . . . . . . . 20

Results ................ 20

Discussion . . . . . . . . . . . . 30 
CHAPTER

PAGE

V . SUMMARY AND IMPLICATIONS . . . . . . . . . . . 37

Summary . . . . . . . . . . . . . . 37

Implications . . . . . . . . . . . . . 39

Clinical

Research

BIBLIOGRAPHY . . . . . . . . . . . . . . . . . . . . 4 42

APPENDICES . . . . . . . . . . . . . . . . . . . 45 


\section{LIST OF TABIES}

TABLE

PAGE

I Experimental Sequence . . . . . . . . . . . . 18

II Results as Indicated by Measuring Latency of Response

to Presented Stimuli . . . . . . . . . .

III Results of a Comparison of the Study of $\mathrm{krug}$ et al.

(1978) with this Investigation . . . . . . . . 


\section{IIST OF FIGURES}

FIGURE

1. Z-score Profiles of the Reaction Times of Subject A to the Auditory and Visual Stimulus Conditions Presented Individually . . . . . . . . . . . 21

2. Z-score Profiles of the Reaction Times of Subject B to the Auditory and Visual Stimulus Conditions Presented Individually . . . . . . . . . . 22

3. Z-score Profiles of the Reaction Times of subject C to the Auditory and Visual stimulus Conditions Presented Individually . . . . . . . . . . .

4. Z-score Profiles of the Reaction Times of Subject D to the Auditory and Visual Stimulus Conditions Presented Individually . . . . . . . . . . . .

5. Z-score Profiles of the Reaction Times of Subject $\mathbf{E}$ to the Auditory and Visual Stimulus Conditions Presented Individually . . . . . . . . . 25

6. Z-score Profiles of the Reaction Times of Subject $F$ to the Auditory and Visual Stimulus Conditions Presented Individually . . . . . . . . . 26

7. Z-score Profiles of the Reaction Times of Subject G to the Auditory and Visual stimulus Conditions Presented Individually . . . . . . . . . . 
viii

FIGURE

PAGE

8. $\mathrm{z}$-score Profiles of the Reaction Times of Subject $\mathrm{H}$ to the Auditory and Visual Stimulus Conditions Presented Individually . . . . . . . . . . . 
CHAPTER I

INTRODUCTION AND STATEMENT OF PURPOSE

\section{Introduction}

Kanner first used the term "early infantile autism" in 1943 to label a clinical synarome. He considered the primary identifying characteristic to be inability to relate to other people and situations in an ordinary manner (Kanner, 1957). Creak (1963) defined schizophrenic syndrome in children by listing nine characteristics. These nine characteristics include impairment of relationships with people, unawareness of personal identity, preoccupation with objects and sameness, deficient speech, abnormal perceptual experience and retardation with areas of normalcy (see Appendix A). Hermelin and O'Connor (1970) stated that this schizophrenic syndrome in children described by Creak characterizes what other authors refer to as autism.

The parent of an autistic child frequently is first concerned that his/her child may be deaf or hard-of-hearing (Rimland, 1964). In contrast, test results usually show autistic children's hearing to be within normal limits; responses to auditory stimuli, however, are systematically different from session to session and from stimuli to stimuli (Koegel, 1976).

Not only are responses to auditory stimuli different from the 
"normal" population, but abnormal response to sensory stimuli in general can be considered a primary characteristic of early infantile autism (Hermelin and O'Connor, 1970). Perceptual skills are crucial to a developing infant. Walters and Parke (1965) considered distance receptors for vision and hearing to be crucial for the development of social responsiveness. However, many researchers report autistic children are more dependent on the proximal senses of touch, taste and smell than on audition and vision (Goldfarb, 1961; Rimland, 1964; Wing, 1966). It is hypothesized then, that the sensory and/or processing difficulties of autistic children are closely related to the behavioral manifestations of the syndrome (Lovass and Schreibman, 1971), and hence deserve close attention.

The autistic child may over- or underreact to stimuli without apparent consistency. One day the child may be alert to a very low intensity sound stimulus and the next day may appear to ignore it. The child may use a seemingly inappropriate sense in response to his environment (Hermelin and O'Connor, 1970). For example, whereas most children may rely on vision to explore a new toy, the autistic child may use touch.

Rimland (1964) suggested responding may vary across modalities. Studying the perceptual aspects of autism, Lovass, Schreibman, Koegel and Rehm (1971) showed evidence that some autistic children attend to only one dimension of a multidimensional stimulus. Such a response was termed stimulus overselectivity or overselective attention. More specifically, it is defined as the "phenomena of responding to only a few cues from a larger range of availablecues" (Wilhelm and Lovass, 
1976). Some researchers (Krug, Arick, Workman and Pelson, 1978b; Konstantareas and Blackman, 1978) have referred to the modality overselected by autistic children as a preferred modality. It appears after reviewing the literature that the terms "overselected modality" and "preferred modality" are used to describe the same phenomena. Preferred modality, however, seems to imply that the autistic child is better able to use one modality than another.

There is conflicting evidence concerning the relationship of an auditory or visual modality preference to the acquisition of language through speech or manual communication. Konstantareas and Blackman (1978) presented evidence that those who select the auditory modality are potential speakers, whereas those who select the visual modality would be more successful with manual communication. Krug et al. (1978b) found a lack of evidence to support this hypothesis.

Clinical observations of Lovass et al. (1971) suggested these children respond to cues of a particular modality on one occasion, but not on another. Considering the possible inconsistency of reaction to sensory stimuli (Hermelin and O'Connor, 1970; Wing, 1972; Koegel, 1976), there is a need to determine the consistency of overselectivity before it can be determined if a preferred modality exists. Such information will be useful in planning programs for autistic children.

\section{Statement of Purpose}

The purpose of this study was to determine if the phenomenon of overselection or the absence of overselection is consistent over time as determined by measuring the latency of response to the 
presentation of the stimuli.

The questions asked were:

1. Does an autistic child consistently exhibit overselection or the absence of overselection, two times over a period of seven days, as indicated by measuring the latency of response to the stimulus modalities of audition and vision?

2. Does an autistic child overselect the same modality, two times over a period of seven days, as indicated by measuring the latency of response to the stimulus modalities of audition and vision?.

\section{Definition of Terms}

Autism: Refers to the clinical syndrome of a child exhibiting autistic-like behavior as described by Creak (1963) as presented in Appendix A. When reporting other researchers' studies, their terminology will be used. For this investigation the subjects were diagnosed as autistic through the use of the Autistic Behavior Checklist (Krug et al., 1978b) (Appendix B) and a previous psychiatric evaluation.

Preferred Modality: The same phenomenon as stimulus overselectivity or overselective attention. "Preferred modality" seems to imply, however, that the autistic child is better able to use one modality than another. This researcher will use the term "overselected modality" unless referring to a study reported by another researcher.

Sensory dominance: The phenomenon in which an organism uses one sensory channel more than others to gain information about the environment.

Stimulus complex: All cues of different modalities presented simultaneously.

Stimulus overselectivity or overselective attention: "The phenomena of responding to only a few cues from a larger range of available cues" (Wilhelm and Lovass, 1976). In the classic studies of overselection (Lovass et al., 1971; Lovass and Schreibman, 1971), it refers to responding to one modality more frequently than another. In this investigation it refers to responding to one modality faster than another. 
This review was drawn from the major studies in the area of overselectivity of auditory and/or visual modalities in autistic children. The results of the assessment of the psycholinguistic skills of autistic children will also be reported. Additionally, two studies reported here investigated the relationship of the modality selected to relative success in manual or oral communication.

\section{Studies of Overselection of Autistic Children}

Creak (1963) listed abnormal response to sensory stimuli and underdeveloped or absent speech and language as part of the behavioral criteria describing autism. Hermelin and O'Connor (1970) agreed that deficient language and speech skills are a central characteristic of autism. This may be due, in part, to perceptual deficits found in autistic children. All the intricacies of speech and language development have not been uncovered, but children's interaction with their environments is crucial for developing speech and language skills. When children are unable to interact "normally" with their environment, deficient speech and language skills may result. Studies of overselectivity seem to indicate autistic children may be perceiving and responding to their environment differently than other children. This surely could be a factor in their deficiencies in speech and language 
skills.

In 1882 Abbott first discussed the concept of sensory dominance (Hermelin and O'Connor, 1970). Sensory dominance varies from species to species. Within the human species, sensory dominance alters as development progresses (Hermelin and O'Connor, 1970). Indeed, according to Piaget (1952), the development of intelligence is directly related to the way a child perceives and responds to his environment.

There may be a hierarchical organization of sensory channels in individuals in general, with one channel more easily responded to than another (Goldfarb, 1956; Schopler, 1966; Hermelin and O'Connor, 1970). Experiments have been conducted to investigate the responsiveness of autistic children to input through the various sensory modalities. Experimental results have varied. Several of the major relevant studies will be discussed separately.

One of the earliest studies dealing with overselectivity reported a dominance of the visual sensory channel in autistic subjects. In 1964 Hermelin and O'Connor (1970) compared ten autistic and ten "subnormal" children. In the study, two stimulus modalities were presented simultaneously to the child: 1) auditory and visual; 2) tactile and visual, or 3) auditory and tactile. They reported the highest response to the visual modality for both groups. The second highest response for the autistic sample was to tactile stimuli, whereas auditory was second for the "subnormals."

Later studies did not find a particular dominant modality, but did yield further evidence of overselectivity occurring in autistic children. In 1971 Lovass et al. conducted a study dealing with 
selective responding. Their subjects consisted of five autistic, five retarded and five "normal" children. The autistic group was functioning at a low level. They were essentially nonverbal, institutionalized and considered to be within the "lower one third of the psychotic continuum." In this study, the stimulus complex consisted of simultaneous presentation of auditory, visual, tactile and temporal cues.

The subjects were first trained to respond to the entire stimulus complex. Afterwards, individual single components were presented randomly to determine which stimuli in the complex controlled the response. Each test trial was preceded and followed by a presentation of the stimulus complex. Ten test sessions were completed with no more than two tests per day and no less than one every third day. A fixed ratio reinforcement schedule was used for every fourth response to the total stimulus complex and the subjects were reinforced for every response to a single stimulus. The results of this study showed the autistic subjects responded to one dimension of the stimulus, retardates to two and "normals" to all three. Two autistic subjects scored higher for the visual modality and three for the auditory modality. With the continuation of the ten test sessions (up to two sessions per day) and with reinforcement for responses to each individual stimulus, three of the autistic subjects began responding to the originally nonoverselected modality in addition to their initially overselected modality. One subject under auditory control also responded to the visual stimuli; two under visual control responded to the auditory stimuli. This was not the case for all 
the autistic subjects, however. One subject under auditory control decreased his responses to the visual modality. Another subject under auditory control remained essentially the same in his responses to the visual modality. In a third phase of the experiment, Lovass et al. trained previously nonfunctional cues separately and they did acquire control.

Lovass et al. (1971) concluded their study by stating their results did not support the notion of one preferred modality in autistic children. Since, in some cases, the previously nonfunctional modality began to control the response, Lovass et al. stated the overselectivity is due to an attentional factor. There evidently is difficulty in dealing with stimuli in context. Their attention may have been overselective (Lovass et al., 1971; Lovass, 1977), which does not lend support to the idea of a preferred modality. Lovass and Schreibman (1971) did a follow-up study utilizing only two modalities in the stimulus complex, auditory (white noise) and visual (red light). Nine autistic children were tested. These subjects were also at a low functioning level. Of the nine subjects, five were initially under auditory control, three were initially under visual control and one was under the control of the auditory and visual modalities equally.

After ten sessions (up to four sessions per day) with reinforcement for responses to the individual stimuli, the nondominant cue remained nonfunctional for four of the subjects. Two of these subjects remained under the control of the auditory cue and two remained under the control of the visual cue. Two began responding 
to the nondominant, visual cue. For one subject the dominant visual cue lost control to the auditory cue. The subject with a slight selectivity for the auditory modality remained generally under the same stimulus control, as did the subject with no overselective responding. As in the previous study, a nondominant stimulus could be trained separately to gain dominance.

In general, the same conclusion was reached by Lovass and Schreibman (1971). No one modality appeared to be preferred by the autistic children as a group. Both studies incorporated reinforcement of all responses to presentations of a single stimulus over ten sessions and thus learning may have occurred over time. Both of these studies specifically attempted to train the subjects to respond to the nonoverselected modality. The consistency of the modality selected over time was not determined.

Later studies have shown autistic children overselect, not only across modalities, but within the same modality (Koegel and Wilhelm, 1973; Reynolds, Newsom and Lovass, 1974). Wilhelm and Lovass (1976) showed a relationship between the number of cues utilized in a discrimination task and general intelligence level or I.Q. This corresponds to the literature dealing with the overselectivity of "normal" children. It appears as though younger children attend to less in simultaneously presented stimuli than do older children (Levine, 1967; Eimas, 1969; Levine, 1970).

In 1976 Edwards, Shigley and Edwards tested one autistic boy for overselectivity. In this study, the child initially was reinforced for responding to the individual stimuli (auditory or visual) 
and was then presented with the bidimensional complex. The subject was trained to discriminate between a red and a green light. He was reinforced for responding to one and punished for responding to the other. He was trained in the same manner to respond to one tone and not another. The auditory discrimination task was shown to be more difficult than the visual. Once trained, all combinations of the auditory/visual complex were presented to determine to which the boy would respond. He responded only to the two previously reinforced stimuli and never to any other combination. Edwards et al. stated this was contradictory to the theory of overselectivity in autistic children. They stated his responses to both auditory and visual stimuli were under stimulus control, i.e., he simply had learned not to respond to those stimuli for which he had previously been punished. Once again, reinforcement and punishment were shown to be in control of the child's responses rather than overselection, without the influence of learning that can occur through punishment or reinforcement over many sessions.

\section{Mode of Communication of Autistic Children}

Although not all the literature agrees, it appears that some autistic children overselect when presented with two or more stimuli simultaneously. The two studies described below sought to discover if a relationship exists between modality selected and the child's most successful mode of communication. Considering the evidence that overselection occurs more frequently among lower level autistic children, Konstantareas and Blackman (1978) designed an experiment 
to test for a correlation between a "preferred" modality and mode of communication (manual or speech). Since visual and auditory overselection have been reported about equally in the literature, they attempted to discover if overselection could be a predictor of success in manual or oral communication.

Konstantareas and Blackman (1978) utilized five nonverbal or minimally verbal autistic children. The subjects were first trained to respond to the two dimensional complex (auditory and visual) and then were tested with the individual stimuli presented alone. Responses to the individual presentations were not reinforced as they had been in the Lovass et al. (1971) studies. Four out of the five children did overselect, one to the visual modality and three to the auditory modality. The child with the lowest I.Q. overselected to the visual modality. The child with the highest I.Q. did not overselect. In training the nonfunctioning modality, Konstantareas and Blackman (1978) found those who overselected to the auditory modality were least likely to respond to the visual modality.

They also found a relationship between the modality selected and the communication mode responded to more readily in a receptive linguistic task. The subject who responded more to the visual modality also exhibited more response to the sign in the linguistic task. The two subjects who responded more to the auditory stimulus, responded more readily to the spoken word in the linguistic task. The subject who showed no modality overselectivity also showed no preference toward sign or speech. This relationship did not appear to occur in a productive linguistic task. For the productive 
linguistic task, the subjects were required to produce an appropriate sign in response to a word, produce an appropriate word in response to the corresponding sign and to produce the appropriate sign, wurd or both when presented with the target object. The subjects preferred sign in all the conditions. Konstantareas and Blackman (1978) referred to this as a visual-motor preference.

Krug et al. (1978b) did a follow-up study of the Konstantareas and Blackman (1978) study with a larger group of autistic children. The subjects consisted of sixteen autistic children, ten pre-verbal and six verbal. By measuring the latency of response to an auditory or visual stimulus ( 75 watt, 125 volt light and $500 \mathrm{~Hz}$ bell tone) when presented individually, after training as in the classic overselectivity paradigm, a modality "preference" was determined. Four of the subjects selected the visual modality. An auditory "preference" was determined for five of the subjects tested. Seven of the subjects had no significant "preference." In this study, only three of the subjects selected a modality which corresponded to their instructional preference, and hence was not sufficient to support a relationship between selected modality and instructional preference. Once again there is more evidence that overselectivity occurs in some autistic children, but there is conflicting evidence as to whether their modality selected corresponds to their successful communication mode.

\section{Psycholinguistic Studies with Autistic Children}

The following studies are included as they provide some indication of the level of functioning of the perceptual systems of 
autistic subjects, unrelated to overselecting. The studies use the term "psychotic" for autistic children. As noted, these children can be considered to be autistic as diagnosed by Creak's (1963) criteria.

The Illinois Test of Psycholinguistic Abilities (ITPA) was administered to a group of "normal," "subnormal," and "psychotic" children by Tubbs (1966). The "psychotic" children were institutionalized and diagnosed according to Creak's criteria (1963). These children had a minimum mental age of 2.5 years in order to be testable with the ITPA. Even with this precaution, some items were too difficult for these children to obtain a score or they obtained a score much below the lowest "ceiling level."

Overall the "psychotic" children did not perform significantly better on the visual tests than the auditory tests. Specifically, the "psychotic" childxen did not differ from the "normal" or "subnormal" children on visual decoding, visual-motor association and auditory-vocal sequential memory. Association and decoding appeared to be performed relatively adequately by the "psychotic" children, as long as the input was visual. The "psychotic" children showed deficits in association and decoding auditory input or when required to give a vocal response. Consequently theix performances on auditory decoding and auditory-vocal association tests were below that of the "normal" children and about the same as the "subnormal" children. The "psychotic" children were particularly poor at those tests requiring spontaneous output or cross-modal coding (Tubbs, 1966). 
In 1977 Prior repeated the Tubbs (1966) study using the revised ITPA. She tested twenty autistic and twenty retarded children. The autistic children, all of whom were verbal, were divided into $h \perp g h$ and low functioning groups. Prior suggested the lower functioning group was comparable to the "psychotic" children Tubbs (1966) tested in her study. The lower functioning autistic subjects were not found to be functioning within normal limits for any of the psycholinguistic skills, nor was visual input processed better than auditory input. Auditory sequential memory was less impaired than other test performances. The higher functioning autistic group performed better than the lower level subjects on all the subtests except visual closure and visual-sequential memory. This study supported Tubbs' (1966) conclusion that spontaneous output and cross-modal coding are particularly difficult for autistic children.

\section{Summary}

As the review of the literature indicates, not all of the research in the area of overselectivity in autistic children is in agreement. It seems evident that some autistic children do overselect. This may be due to an attentional factor or a modality preference. The autistic child may have difficulties attending to more than one stimulus at a time or he may actually be able to utilize one modality more efficiently than the other. This has tremendous implications for the education of autistic children, not only considering which modality to train or teach to, but also the possibility of the lack of generalization from a prompt to the training 
task (Schreibman, 1975). More specifically, the autistic child may only attend to the prompt and not generalize to the behavior being taught.

The studies reported here do not seem to support the preference of one particular modality over another for autistic children as a group. However, the question still remains: Does an individual autistic child overselect the same modality over time, without being trained to respond to a particular modality? This question is relevant to the education of autistic children whether overselectivity is an attentional factor or indicative of a modality preference. The question is relevant for further understanding of the speech and language deficits of these children and the remediation and training of these skills. The development of speech and language is at least, in part, related to the perceptual and processing skills of audition and vision.

Since so little is really known about autism, research into overselectivity and specifically the consistency of the modality selected, can provide one more bit of information about early infantile autism. 
CHAPTER III

METHODS AND PROCEDURES

\section{Subjects}

The eight children who participated in this study were diagnosed as autistic through the use of the Autistic Behavior Checklist (Appendix B) (Krug, Arick, Almond, 1978a) and a previous psychiatric evaluation. All the children were enrolled in the Portland Public Schools or the Autistic Education Program in Portland, Oregon. The children ranged in age from six years, one month to fifteen years, nine months, with a mean chronological age of nine years, six months. The subjects demonstrated hearing and vision within normal limits as determined by previous medical examination. Profiles of the children are represented in Appendix C.

\section{Instrumentation}

An automatic feeder, as modified by this investigator, with an attached response button was utilized. The auditory stimulus consisted of a bell tone with a fundamental frequency of approximately $500 \mathrm{~Hz}$ and an intensity of $75 \mathrm{~dB}$, as determined by a sound level meter (C scale). The visual stimulus consisted of a $75 \mathrm{w}, 125 \mathrm{v}$ light. Both stimuli were presented from the proximity of the response button. The feeder automatically delivered an item of food, which was 
previously determined to be a high level reinforcer through testing by classroom teachers. The food items were delivered immediately upon pressing the response button. Occasionally the food item was delivered by the experimenter when the equipment malfunctioned.

\section{Experimental Procedures}

\section{$\underline{\text { Pretraining }}$}

The experiment was conducted in a clinic room of the Portland State University Speech and Hearing Clinic. The procedures that follow represent a replication of the study by krug et al. (1978b). The child was conditioned to carry out the task. Each child was seated before the reinforcement apparatus. The experimenter demonstrated a response that resulted in the delivery of a food item. When necessary, the subject was physically prompted until he initiated a response independently. The physical prompt consisted of the most minimal prompt necessary which was faded until no prompt was needed. After two unassisted responses in one minute, the experimental sequence was initiated.

\section{Experimental Sequence}

Each child progressed through the experimental sequence shown in Table I. Steps 3 and 4 of the sequence indicate half the subjects were presented with the auditory stimulus condition first and half with the visual stimulus condition first. Each stimulus condition of the experimental sequence was presented for eight trials. The latency of response for each trial was measured with a stop watch. 
The latency of response was the time span from the presentation of the stimulus to the pushing of the response button. In the case of the no stimulus conditions the time span was measured from the rime the child put the reinforcer in his mouth to the next time he pushed the response button. If the child did not respond within three minutes (180 seconds) the response to that stimulus condition was considered to be extinguished. Each stimulus was presented at random intervals varying from 5 to 15 seconds. All responses to each stimulus condition were reinforced.

The entire procedure was carried out two times over a period of seven days. Each experimental sequence was initiated no sooner than four days apart and no longer than seven days apart. Each experimental:sequence was accomplished in 15 to 25 minutes.

TABLE I

EXPERIMENTAL SEQUENCE

1. No stimuli

2. Auditory and visual

3. Auditory or visual

4. Visual or auditory

5. Auditory and visual

6. No stimuli

It should be noted the planned procedures of this investigation were modified minimally to accommodate subjects B, D, E, F and G. It was necessary to train subjects $D, E, F$ and $G$ to respond to the presentation of the stimulus complex in step 2 of the experimental 
sequence, after they were reinforced for responding to the "no stimulus" condition in Step 1. The training consisted of prompting the subjects to push the response button after presentation of the stimulus complex. Reaction times were measured after the child demonstrated two unassisted button pushes in response to the stimulus complex.

Step 1 in the experimental sequence (no stimulus condition) was eliminated for subject $B$. After training subject $B$ to respond to the "no stimulus" condition, she did not appear to understand she was to respond to the stimulus complex, even after training. The sequence was implemented a second time with the elimination of Step 1. She was trained to respond to the stimulus complex instead of the "no stimulus" condition. The sequence was then completed. This examiner believes these alterations did not affect the results of the investigation.

\section{Data Measurement and Analysis}

Overselection was determined by comparing the reaction times to the auditory and visual modalities presented individually in Steps 3 and 4 of the experimental sequence. The measured reaction times in seconds were converted to z-scores. The z-scores of the visual and auditory modalities were then compared. If one of the stimulus modalities had three or more z-scores (in comparison to the other stimulus modality) slower than one standard deviation from the mean, that stimulus modality was considered to be the slower and hence the nonoverselected modality. The other modality (faster reaction time) was determined to be the overselected modality. 
CHAPTER IV

RESULTS AND DISCUSSION

\section{Results}

The purpose of this study was to determine if the phenomenon of overselection or the absence of overselection in autistic children is consistent over time, specifically on two different days, four to seven days apart. Overselection was determined by analyzing the reaction times to the auditory and visual stimuli presented individually. Comparisons of the number of reaction times that were slower than one standard deviation from the mean determined which modality was responded to faster (see Chapter III). These data are represented in Figures $1-8$.

Usable data were obtained from seven of the eight subjects tested. Data provided by subject $H$ were determined, with consultation with the subject's full-time aide, to be inappropriate for this study because his self-stimulatory behaviors interfered with his reaction times to the stimuli (Figure 8).

The first question asked was: Does an autistic child consistently exhibit overselection or the absence of overselection, two times over a period of seven days, as indicated by measuring the latency of response to the different stimulus modalities? The data from the seven subjects $(A-G)$ indicated four subjects $(B, C, D, F)$ were consistent in not 

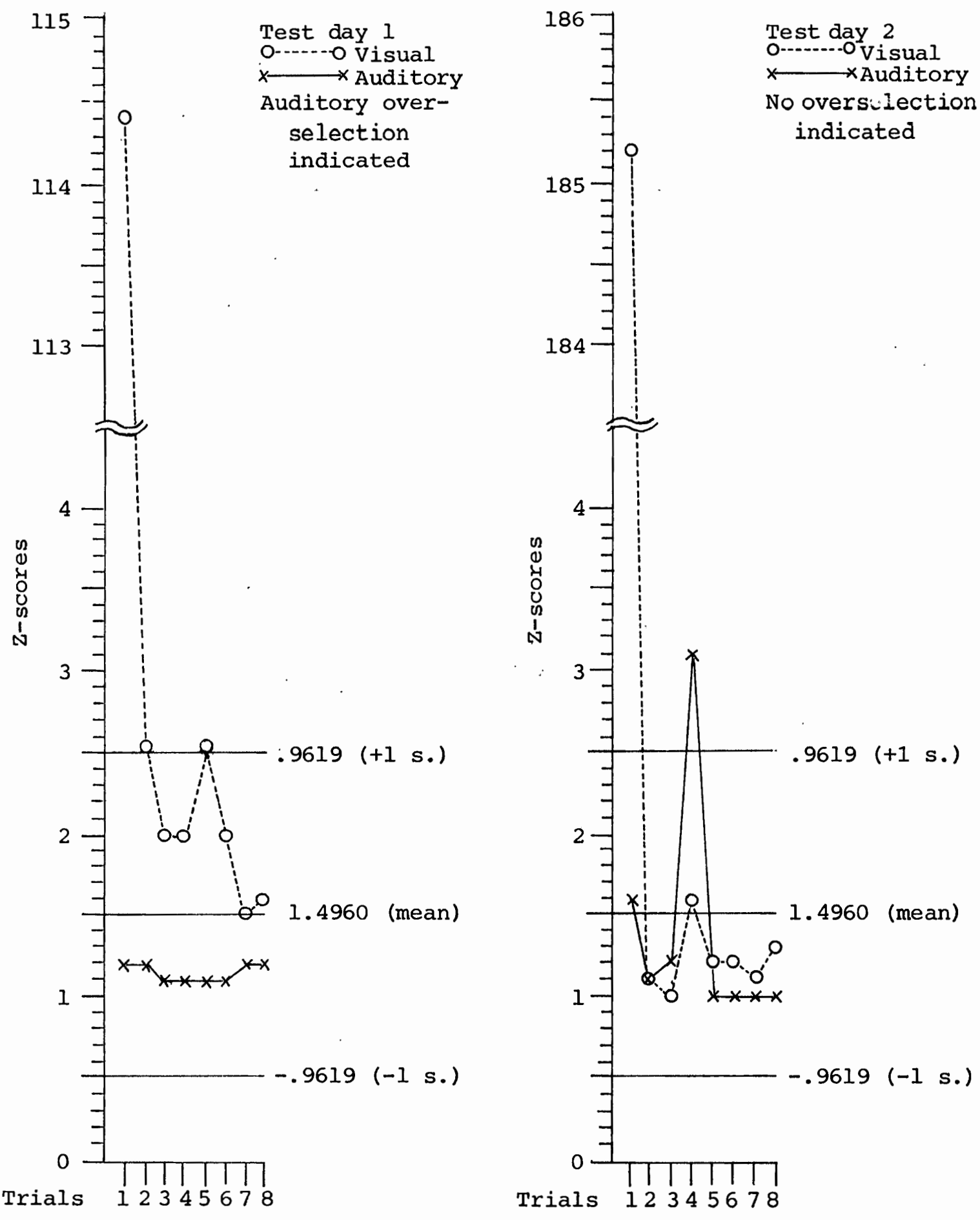

Figure 1. Z-score Profiles of the Reaction Time of Subject A to the Auditory and Visual Stimulus Conditions Presented Individually. 


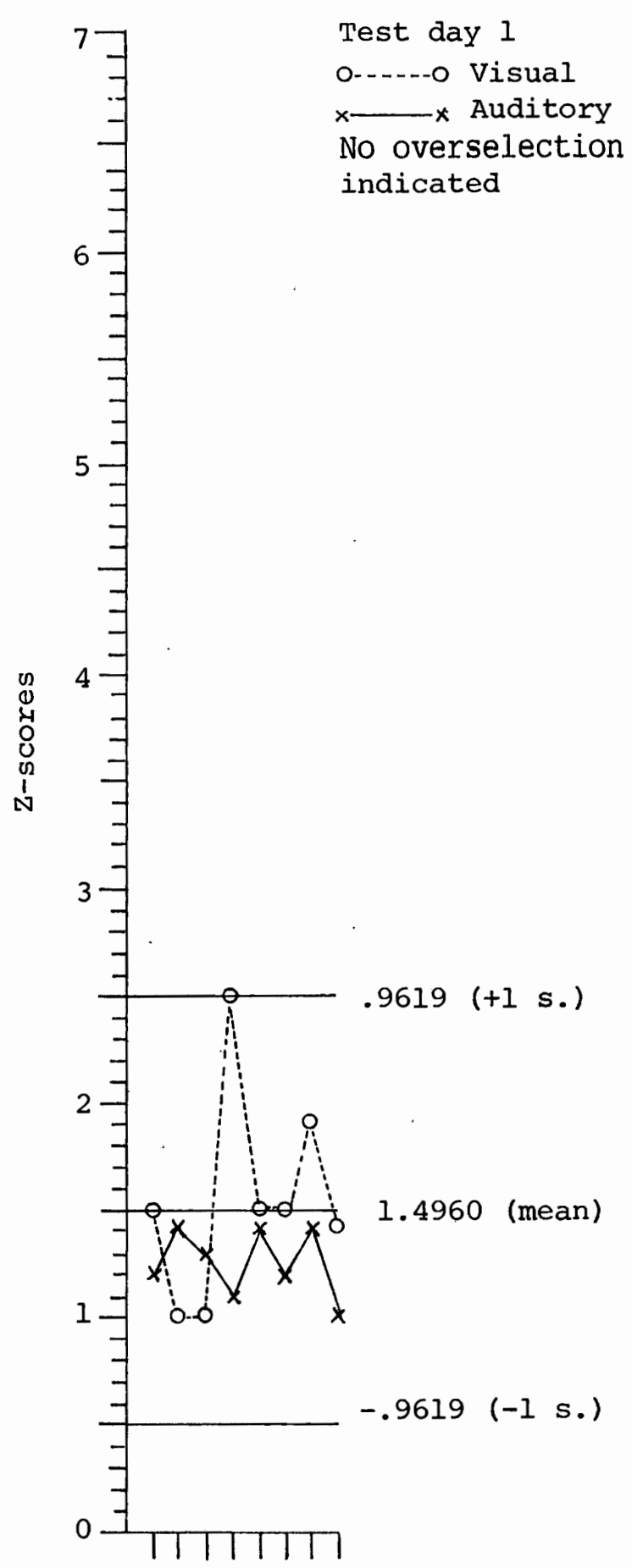

Trials 12345678

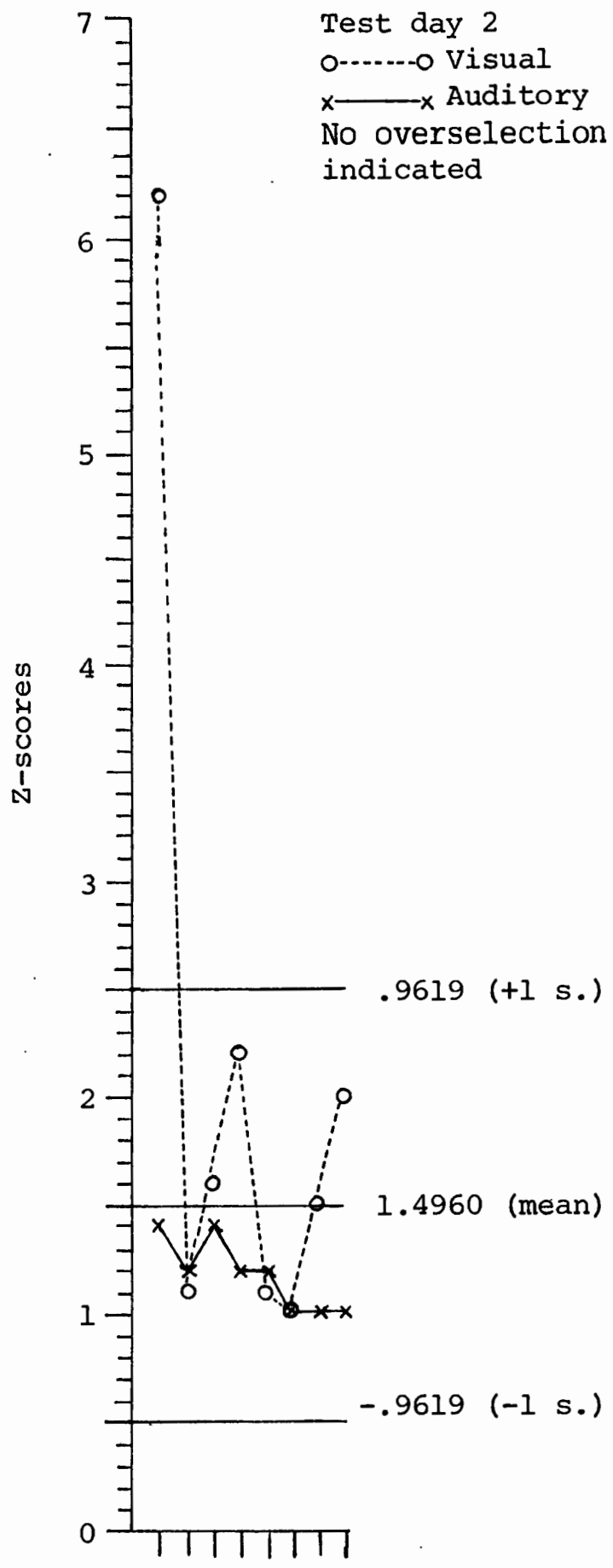

Trials 12345678

Figure 2: Z-score Profiles of the Reaction Times of Subject B to the Auditory and Visual stimulus Conditions Presented Individually. 

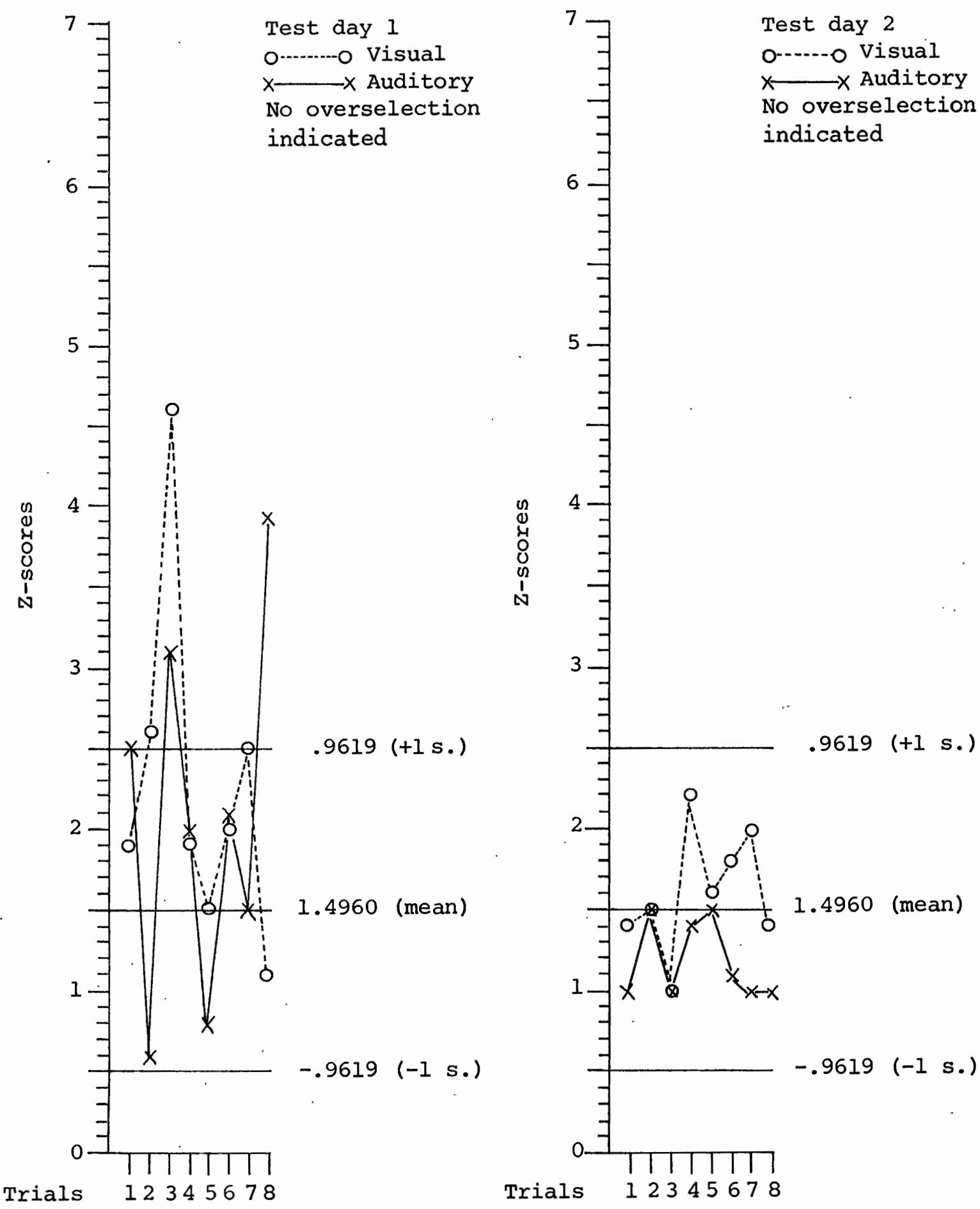

Trials

12345678

Trials

12345678

Figure 3. Z-score Profiles of the Reaction Times of Subject $C$ to the Auditory and Visual stimulus Conditions Presented Indivisually. 


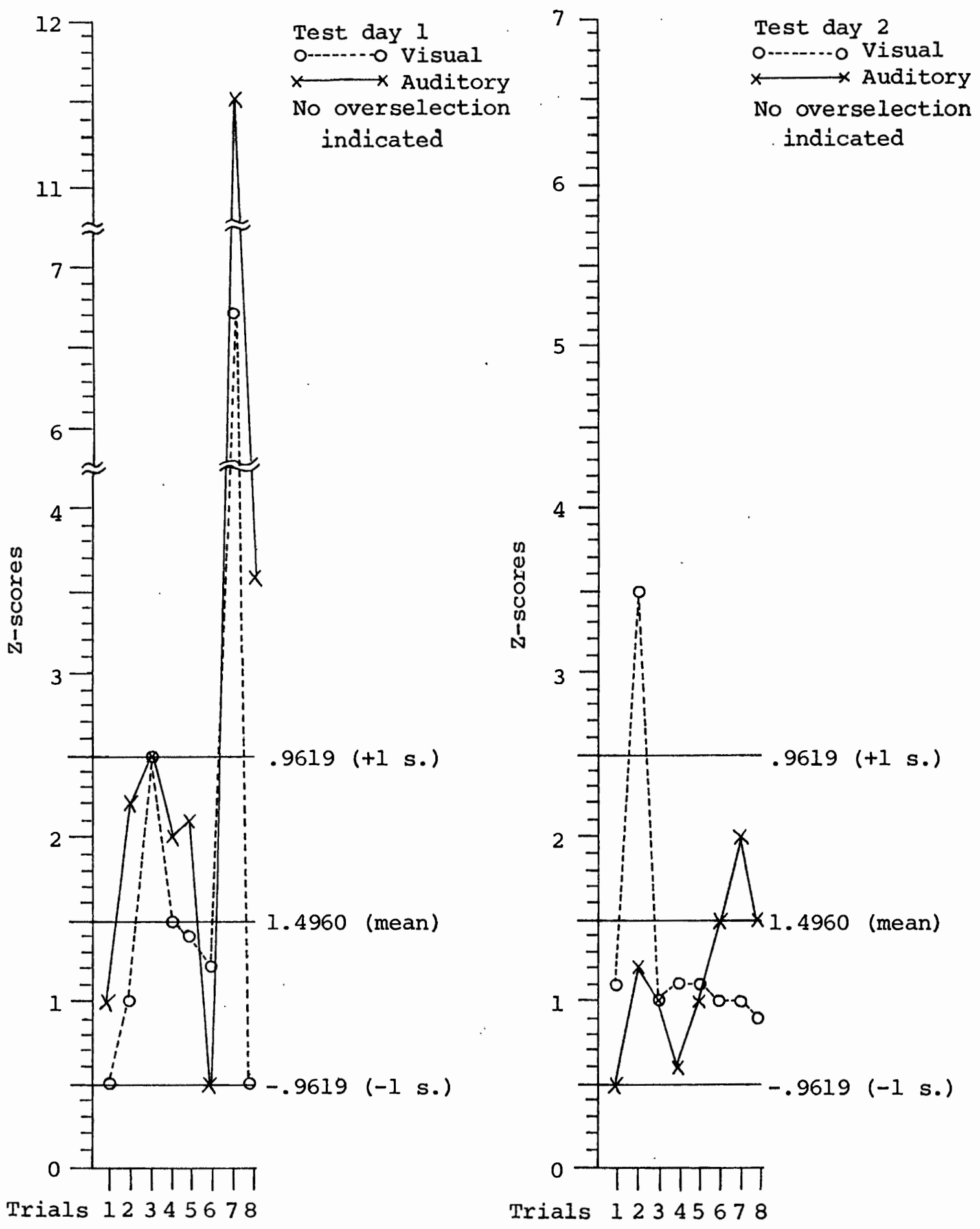

Figure 4. Z-score Profiles of the Reaction Times of Subject D to the Auditory and Visual Stimulus Conditions Presented Individually. 


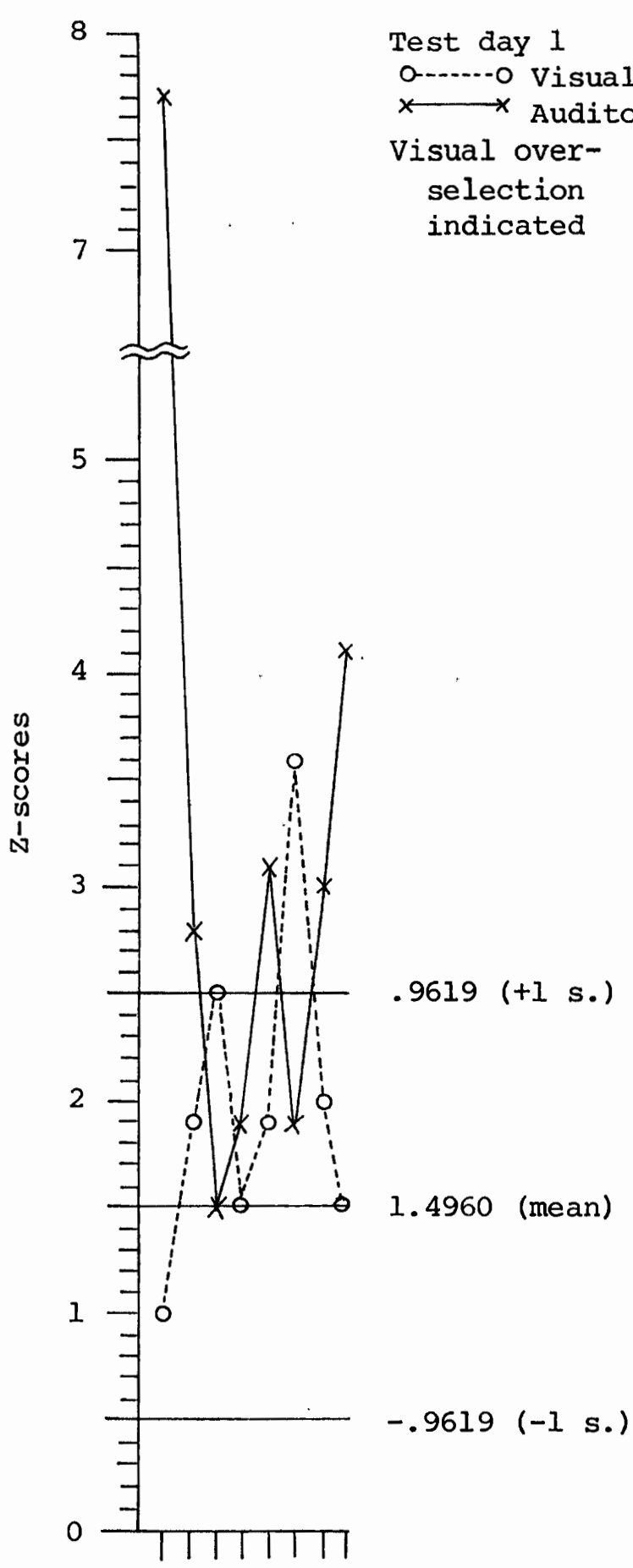

Trials 12345678

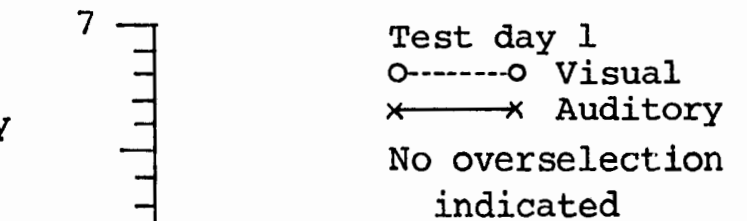
indicated 


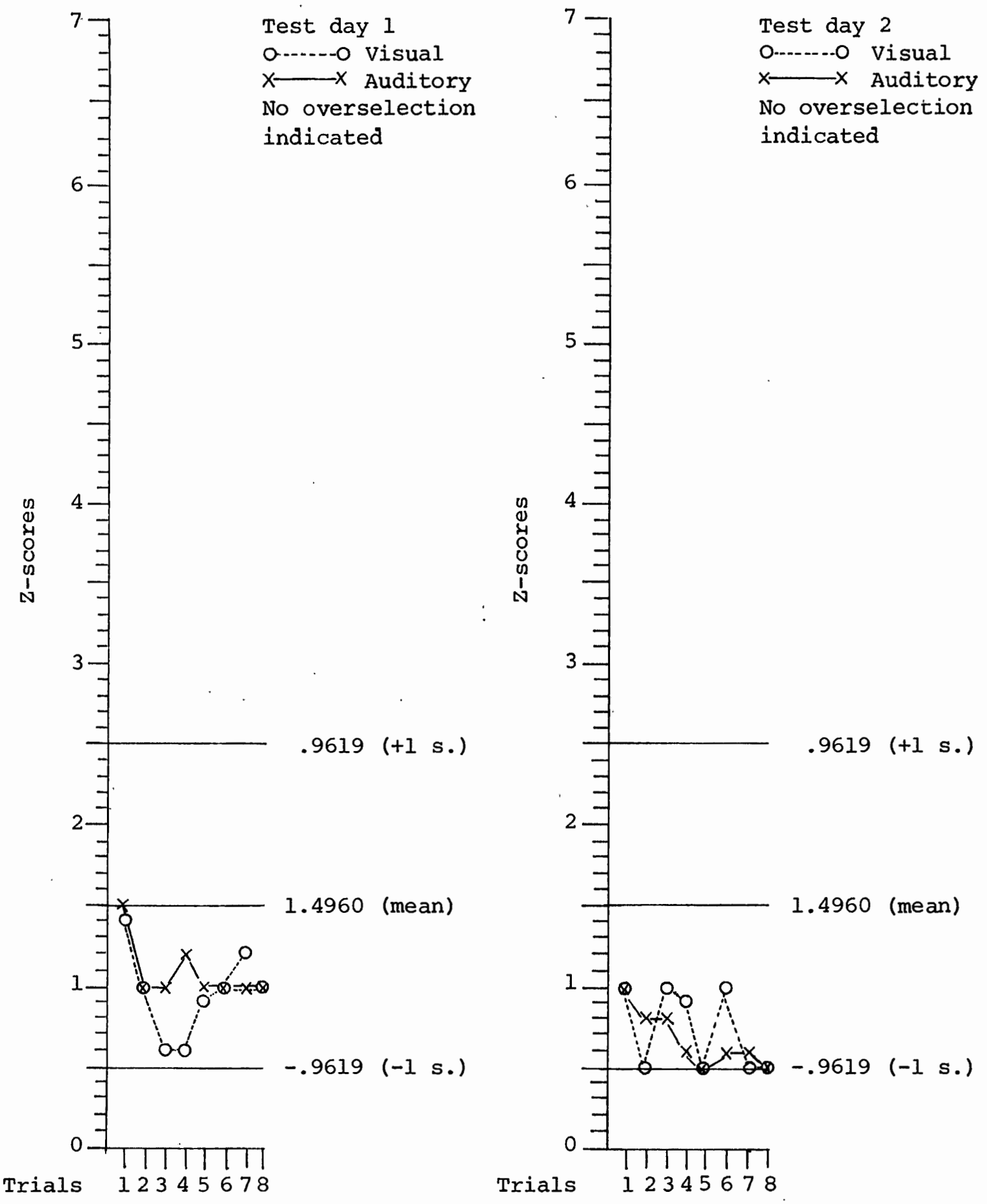

Figure 6. Z-score Profiles of the Reaction Times of Subject $F$ to the Auditory and visual stimulus Conditions Presented Individually. 

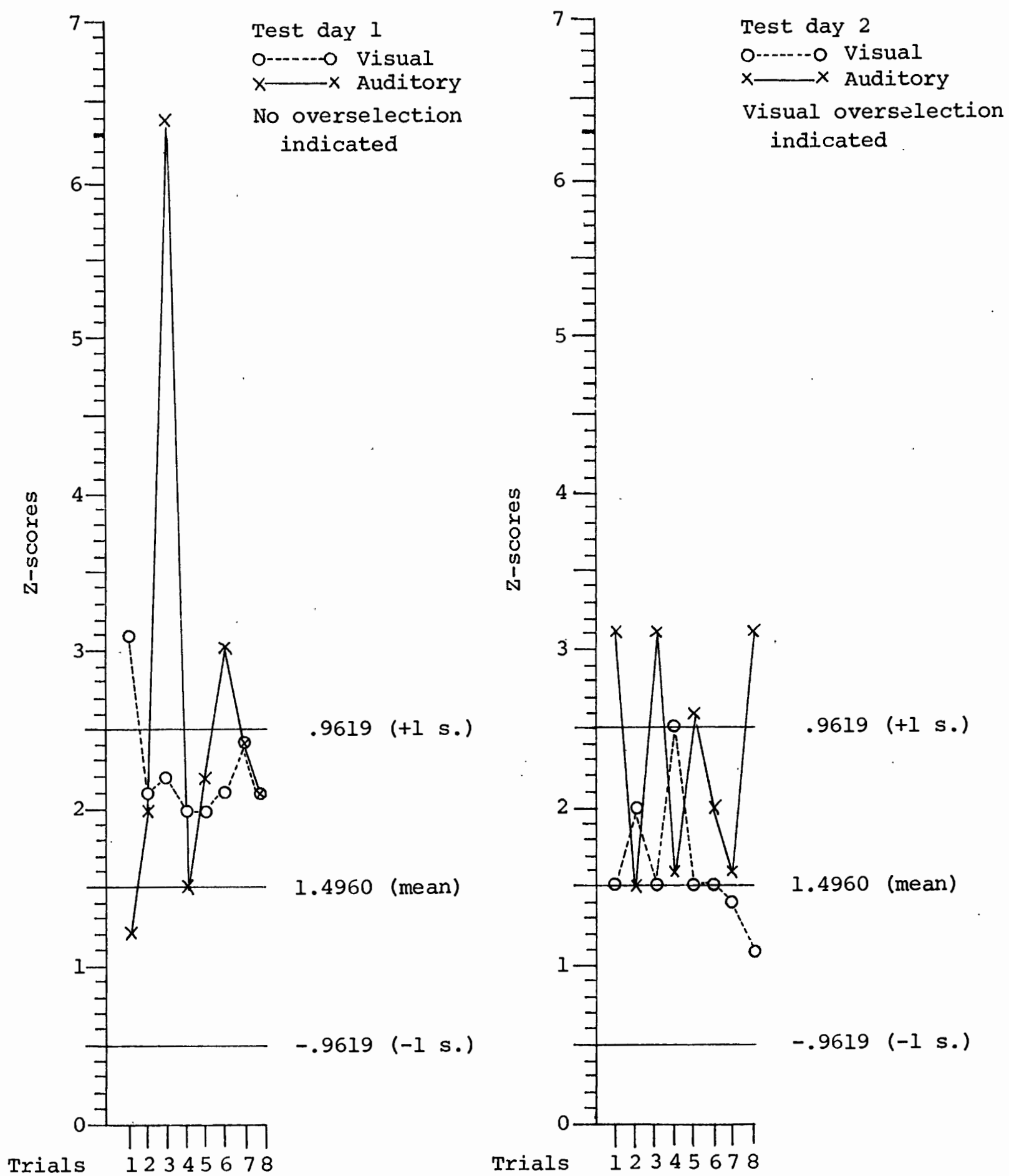

Trials

12345678

Trials $\quad 12345678$

Figure 7. 2-score Profiles of the Reaction Times of Subject $G$ to the Auditory and Visual Stimulus Conditions Presented Individually. 

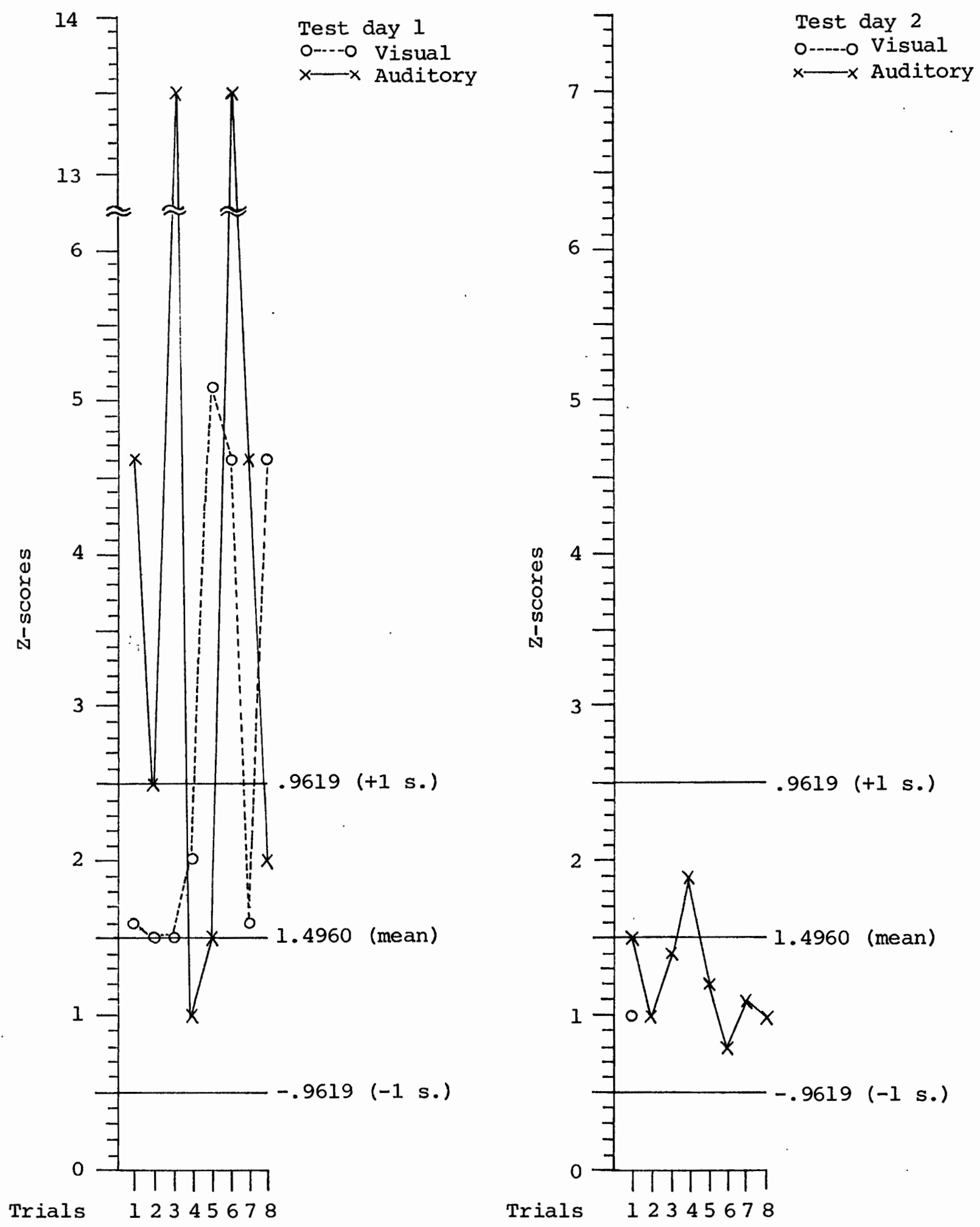

Trials $\quad 12345678$ Trials 12345678

Figure 8. Z-score Profiles of the Reaction Times of subject $\mathrm{H}$ to the Auditory and Visual Stimulus Conditions Presented Individually. 
overselecting on either day, and three subjects (A, E, G) showed inconsistency by overselecting on one test day and not on the other (Figures 1-7). Specifically, regarding the latter group, subject A overselected the auditory modality on the first test day and did not overselect on the second test day; subject $E$ overselected with the visual modality on the first test day and did not overselect on the second test day; subject $G$ did not overselect on the first test day and overselected with the visual modality on the second test day. These results are summarized in Table II.

TABLE II

RESULTS AS INDICATED BY MEASURING IATENCY OF RESPONSE TO PRESENTED STIMULI

$\begin{array}{ll}\text { A } & \text { Auditory overselection } \\ \text { B } & \text { No overselection } \\ \text { C } & \text { No overselection } \\ \text { D } & \text { No overselection } \\ \text { E } & \text { Visual overselection } \\ \text { F } & \text { No overselection } \\ \text { G } & \text { No overselection }\end{array}$

No overselection

No overselection

No overselection

No overselection

No overselection

No overselection

Visual overselection

The second question asked was: Does an autistic child overselect the same modality, two times over a period of seven days, as indicated by measuring the latency of response to the different stimulus modalities? This question could not be answered since no child overselected on both the test days.

In summary, four subjects were consistent in that they did not 
overselect on either test day. Three were inconsistent in that they indicated an overselection on only one of the two test days.

\section{$\underline{\text { Discussion }}$}

A preliminary comment needs to be made regarding the slight modifications of the procedures as described in Chapter III. These modifications did not appear to alter the results of this investigation since they did not affect the reaction times to the presentations of the auditory or visual modalities presented individually. Perhaps other procedures could have prevented the need for modifications.

The data in Appendix D represents the subjects' raw scores obtained in the experimental sequence. Appendix E represents the conversion of these scores to z-scores. The increase of latency of response to step 8 (no stimulus condition) indicates the subjects were under stimulus control for the auditory and visual stimuli.

Many uncontrolled variables could have feasibly caused a subject to respond slower on any particular trial. This was considered insignificant to the overall results. For example, subject $D$ shows this clearly in his response to trials seven and eight for the auditory stimulus and trial seven for the visual condition, on test day 1 (Figure 4). On test day 2, the response to the visual stimulus condition of trial 2 was much slower than to the other trials. These slower responses could have been the result of uncontrolled variables such as an unidentified distraction for the subject or some internal stimuli occurring within the subject. These isolated skewed responses can also be noted to occur with subject $A$, test day 2 , trial 4 of 
the auditory stimulus condition (Figure 1) and subject G, test day 1 , trial 3 of the auditory stimulus condition (Figure 7).

Some subjects may have learned to respond to a single presentation of a stimulus since they were automatically reinforced for a response to the stimulus after a significant time delay. As reflected in the data of subjects $A$ (test days 1 and 2) and $B$ (test day 2) (Figures 1 and 2), these two subjects appeared to learn to respond to the visual cue after their response was reinforced. The first response may have been random responding since it occurred such a long interval of time after the stimulus was presented.

This investigator believes a different research design may have yielded different results for subject $A$ on test day 1 (Figure 1) if reinforcement had not been given for the responses to the individual stimuli. The auditory responses were always faster (although they did not meet the criteria for overselection), but the subject appeared to learn to respond to the visual stimuli over the eight trials. Perhaps this subject would not have responded at all to the visual stimuli if the stimulus conditions were presented for short, discrete periods of time.

A similar "learning curve" is seen in the reaction times of subject $B$ on test day 2 (Figure 2). Most of the auditory responses were faster (although they did not meet the criteria for overselection) and the subject may have learned to respond to the visual cue. Subject $\mathrm{C}$ did not overselect on either test day (Figure 3). This is clearly seen on test day 1 . The auditory and visual reaction times are relatively equally distributed on the graph. On test day 2, 
however, the reaction times to the auditory stimuli were all faster than the reaction times to the visual stimuli except for two trials, which were equal. This could possibly indicate an overselection, but does not meet the criteria for overselection.

Subject E, test day 1, showed evidence, again, of possibly learning to respond to the auditory stimulus (Figure 5). The subject's response times became generally faster after the first presentation. Since the auditory reaction times did not continually get faster but did vary considerably, the first reaction time may represent the operation of an aforementioned uncontrolled variable. Perhaps the first reaction time was slower due to an uncontrolled variable and not due to learning factors. The auditory reaction times remained slower overall than the visual reaction times, and met criteria for overselection. On test day 2 , subject $\mathrm{E}$ clearly indicated no overselection. The reaction times were clearly clustered together about the mean.

Subject F also clearly indicated no overselection (Figure 6). All reaction times were clustered close together and were all at or faster than the mean.

Inconsistent modality overselection occurred in three of seven subjects. Additionally four did not overselect on either test day. This seems to indicate that more caution is needed when using the term "preferred modality" in connection with overselection of autistic children. Konstantareas and Blackman (1978) reported a correlation between the acquisition of speech and an auditory overselection and between the acquisition of manual communication and a visual 
overselection. They reported this correlation only in the receptive tasks, not in the production tasks. However, Krug et al. (1978) did not find evidence to support such a correlation. Inconsistency of the phenomena of overselection partially may explain the lack of correlation as reported by Krug et al. If a child's overselection tendencies, in fact, vary from day to day, it would seem unlikely to find a direct correlation between the overselection on any one day and the child's overall mode of communication.

Further evidence of inconsistency is seen by comparing the results of the Krug et al. (1978) study with the results of the present investigation. Many of the same subjects were utilized in both investigations. The subjects were tested for overselection on one test day in the Krug et al. study. The modalities overselected by the subjects in the study by Krug et al. in 1978 are compared to the modalities overselected by the subjects in this investigation, approximately one year later (Table III). Although question two, concerning the consistency of the modalities selected could not be answered by this investigation, it is interesting to note comparisons of the modalities overselected by the children in this investigation and in the Krug et al. (1978) investigation. Subjects $A$ and $E$ both overselected with different modalities in the Krug et al. (1978) study and test day I (Walker, 1979). Subject G overselected with the visual modality in the Krug et al. study and test day 2 of this investigation. Subjects B and C overselected in the Krug et al. study and did not overselect on either test day of this investigation. Subject $D$ consistently did not overselect in either investigation (Table 
III). Inconsistency is further supported by comparing these subjects over the one year period. Perhaps some of this inconsistency may be due to developmental changes over the year. Hermelin and O'Connor (1970) reported sensory dominance may alter as development progresses in the "normal" child.

\section{TABLE III}

RESULTS OF A COMPARISON OF THE STUDY OF KRUG ET AL. (1978) WITH THIS INVESTIGATION

\begin{tabular}{|c|c|c|c|}
\hline subject & Krug et al. (1978) & $\begin{array}{c}\text { Walker (1979) } \\
\text { test day } 1\end{array}$ & $\begin{array}{c}\text { Walker (1979) } \\
\text { test day } 2\end{array}$ \\
\hline
\end{tabular}

$\begin{array}{llll}\text { A } & \text { Visual } & \text { Auditory } & \text { No overselection } \\ \text { B } & \text { Auditory } & \text { No overselection } & \text { No overselection } \\ \text { C } & \text { Auditory } & \text { No overselection } & \text { No overselection } \\ \text { D } & \text { No overselection } & \text { No overselection } & \text { No overselection } \\ \text { E } & \text { Auditory } & \text { Visual } & \text { No overselection } \\ \text { F } & \text { Not tested } & \text { No overselection } & \text { No overselection } \\ \text { G } & \text { Visual } & \text { No overselection } & \text { Visual }\end{array}$

While the results of this investigation do not support the concept of a preferred modality for autistic children as indicated by their overselection, they are consonant with Lovass' (1977; Lovass et al., 1971) explanation of overselection as attributable to an attentional factor. Overselection does not imply an ability to use one modality more efficiently than another, but implies the operation of a more random attentional factor. The child simply may attend to a modality on one day and not on another. The clinical observations of Lovass (1971), suggesting an autistic child may respond to a particular modality on one day and not on another, appears to 
be supported by this investigation. The inconsistency of reaction to sensory stimuli as noted by Hermelin and O'Connor (1970), Wing (1972) and Koegel (1976) seems to apply to the phenomenon of overselection in autistic children.

As previously implied, results of the study by Krug et al. (1978) and this study indicate that use of overselection as a possible indicator of the autistic child's most successful role of communication is premature. This implication, however, does not negate the importance of the knowledge that some autistic children overselect. It is still useful information to be used in the management and educational planning of autistic children. It is important to realize the child may not obtain information from different environmental cues simultaneously as a "normal" child does. The autistic child may indeed not generalize from the prompt in a learning situation (Schreibman, 1975). For example, if a light was presented as a prompt to respond to a tone for auditory testing, the autistic child may not generalize the required response to the tone as most "normal" children would.

It is, however, premature to implement teaching procedures through one particular overselected modality unless that modality has been consistently overselected over time by the individual child in question. It appears that one test for overselection may not indicate what the child will attend to the next day.

The results of this study and others (Lovass and Schreibman, 1971; Konstantareas and Blackman, 1978; Krug et al., 1978) indicate not all autistic children overselect. Four of the subjects in this 
investigation did not overselect on either test day. Implications from the studies of overselection cannot be applied to all autistic children. For those who do overselect, the implications must be considered in light of the possible inconsistency of the phenomenon of overselection. 
CHAPTER V

SUMMARY AND IMPLICATIONS

\section{Summary}

A review of the literature indicated that not all of the research in the area of overselectivity of autistic children has been in agreement. It does seem evident that some autistic children overselect. This could be the result of an attentional factor or a modality preference. This has important implications for the education of autistic children. In the light of the inconsistency of autistic children's reactions to sensory stimuli (Hermelin and O'Connor, 1970; Wing, 1972; Koegel, 1976) this investigator believed there was a need to determine if overselection is consistent before referring to the overselected modality as a preferred modality or comparing overselected modalities with the child's mode of communication (manual or speech). This investigation constituted a replication of the methodology of $\mathrm{Krug}$ et al. (1978). The major difference in this investigation was it was conducted on two days for comparison of results over time. The study by Krug et al. was conducted on one day. In this investigation no comparison was made with the child's mode of communication.

The questions posed by this study were:

1. Does an autistic child consistently exhibit overselection or the absence of overselection two times over a period of seven days, as indicated by measuring the latency of response to the different stimulus modalities? 
2. Does an autistic child overselect the same modality, two times over a period of seven days, as indicated by measuring the latency of response to the different stimulus modalities?

To answer these questions the reaction times of eight autistic subjects to various stimulus conditions were measured. Each child progressed through the following experimental sequence on two test days, four to seven days apart:

1. No stimulus condition

2. Auditory plus visual condition

3. Auditory or visual stimulus condition

4. Visual or auditory stimulus condition

5. Auditory plus visual condition

6. No stimulus condition

The reaction times to the auditory stimulus were compared with the reaction times to the visual stimulus for each test day. By comparing the number of reaction times slower than the mean, the modalities responded to faster were determined. This was considered to be the overselected modality. These results were compared for each child individually for the two test days to determine if the phenomenon of overselection was consistent over time.

In answer to question one, the data indicated four subjects were consistent in that they did not overselect on either test day. Three were inconsistent in that they indicated an overselection on only one of the two test days. Question two could not be answered by this investigation since no subject overselected on both test days.

The results of this investigation do not support the concept of a preferred modality for autistic children as indicated by their overselection. They are consonant with Lovass' (1977; Lovass et al., 1971) explanation of overselection as attributable to an attentional 
factor. The child may simply attend to a modality on one day and not another. These results are not surprising considering the general inconsistency of reaction to sensory stimuli as noted by Hermelin and O'Connor (1970), Wing (1972) and Koegel (1976).

This investigator believes it may be premature to implement teaching procedures through one particular overselected modality unless that modality has been consistently overselected over time by the individual child in question.

\section{Implications}

\section{Clinical}

The results of this investigation suggest the phenomenon of overselection of autistic children may not be appropriate for determining a "preferred learning modality" or for predicting a preferred mode of communication. Not all autistic children overselect and those who do, may not do so consistently. No child in this study overselected on both days. Overselection may simply reflect varying attention. One day the autistic child may attend to a particular modality and the next day he may not. Although it seems overselection does not reflect a preferred modality, it does have important implications for the management and educational planning of autistic children. Some autistic children may not obtain all the information that is available to them from their environment. It must be stressed, however, that implications from the studies of overselection cannot be applied to all autistic children. Not all autistic children overselect. This investigation clearly supported this. Only three 
of the subjects in this study overselected on either test day. A clinician managing an autistic child should be aware that the child may not generalize from a prompt to the learning situation. The autistic child may not perceive all the cues presented to him. It should not be assumed, however, that this is the case for all autistic children. Each child must be measured on an individual basis with a consideration of his response to input modality.

$\underline{\text { Research }}$

It is suggested for further research that this study be replicated over longer intervals of time of six months to a year. The effects of developmental factors on overselection could then be assessed. If this study were replicated with a larger number of autistic subjects, generalizations would be more feasible. This study could also be replicated to compare the overselection tendencies of "normal," mentally retarded and autistic children with the same mental age, over time. The overselection tendencies of lower functioning autistic children could be compared with the overselection tendencies of higher functioning autistic children, over time. Perhaps correlations could be found between the functioning level of the child and his overselection tendencies.

The need for adaptations of the experimental procedures as mentioned in Chapter III, and the effect of learning factors as mentioned in Chapter IV, could possibly be alleviated in subsequent studies by presenting stimuli for a discrete, short interval of time. The child could either respond to the stimulus or not. The percentage 
of responses to the auditory presentations could be compared to the percentage of responses to the visual presentations. For such a procedure, the child could be trained initially to respond to the stimulus complex. Each individual auditory or visual stimulus could then be presented randomly interspersed with presentations of the stimulus complex. Perhaps the complex could be reinforced on a fixed ratio interval schedule with no reinforcement for the responses to single stimuli to decrease the effects of learning. The procedure could be repeated a greater number of times if no reinforcement is provided for responses to the auditory and visual stimuli presented individually. This could help determine if an autistic child overselects one modality more frequently than another. Determinations could also be made as to how often overselection occurs. The information obtained would provide further evidence related to the consistency or inconsistency of overselection of autistic children.

The results of this investigation indicate a smaller incidence of overselection in autistic children than others (Hermelin and O'Connor, 1970; Lovass et al., 1971; Lovass and Schreibman, 1971; Konstantareas and Blackman, 1978). This may be due to research design. This investigator believes research design must be carefully investigated for each study of overselection in order to obtain the clearest picture of what the autistic child is actually demonstrating.

In conclusion, due to the general difficulty of testing autistic children, much of the information and many of the theories dealing with autism are inferential. In light of this, much more research is needed and inferences from existing research must be made cautiously and remain in the realm of theory and not fact. 
CREAK, M. Childhood psychosis, a review of 100 cases. Brit. J. Psych., 109, 84-89 (1963).

EDWARDS, J., Shigley, R., and Edwards, R. A case report of an autistic boy: selective responding to components of bidimensional visual and auditory stimuli. J. of Autism and Childhood Schizophrenia, $6,139-146$ (1976).

EIMAS, P. Multiple-cue discrimination learning in children. Psychol. Rec., 19, 417-424 (1969).

GOLDFARB, W. Receptor preference in schizophrenic chilaren. Arch. Neurol. Psychiat., 76, 643-653 (1956).

GOLDFARB, W. Childhood Schizophrenia. Cambridge, Mass.: Harvard University Press (1961).

HERMEIIN, B., and O'Connor, N. Psychological Experiments with Autistic Children. New York: Pergamon Press (1970).

KANNER, L. Autistic disturbances of affective contact. Nerv. Child, $2,217-250$ (1943).

KANNER, L. Child Psychiatry. Springfield, Ill.: Charles Thomas (1957).

KOEGEL, R. Identification of consistent responding to auditory stimuli by a functionally "deaf" autistic child. J. of Autism and Childhood Schizophrenia, 6, 147-156 (1976).

KOEGEL, R., and Wilhelm, H. Selective responding to the components of multiple visual cues by autistic children. J. Exp. Child., $15,442-453$ (1973).

KONSTANTAREAS, M., and Blackman, A. "Assessing Preferred Communication Training Modalities in Non-Verbal Autistic Children." Unpublished paper presented at conference of the Canadian Society for Autistic Children (1978).

KRUG, D., Arick, J., and Almond, P. Behavior checklist for identifying severely handicapped individuals with high levels of autistic behavior. Unpublished manuscript, Portland State University, Portland, Oregon (1978a). 
KRUG, D. , Arick, J., Workman, J., and Pelson, R. "Reaction Times to Auditory and Visual Stimuli and their Prediction of Speech and Sign Language Learning Rates." An unpublished paper (1978b).

LEVINE, M. The size of the hypothesis set during discrimination learning. Psychol. Rev., 74, 428-430 (1967).

LEVINE, M. Human discrimination learning: the subtest sampling assumption. Psychol. Bull., 74, 397-404 (1970).

LOVASS, O. The Autistic Child: Language Development Through Behavior Modification. New York: Irvington Publishers, Inc. (1977) .

LOVASS, O., and Schreibman, L. Stimulus overselectivity of autistic childxen in a two stimulus situation. Behav. Res. and Therapy, 9, 305-310 (1971).

LOVASS, O., Schreibman, L., Koegel, R., and Rehm, R. Selective responding by autistic children to multiple sensory input. J. Abnorm. Psychol., 77, 211-222 (1971).

PIAGET, J. The Origins of Intelligence in Children. New York: International University Press (1952).

PRIOR, M. Psycholinguistic disabilities of autistic and retarded children. J. Ment. Defic. Res., 21, 37-45 (1977).

REYNOLDS, B., Newsom, C., and Lovass, O. Auditory overselectivity in autistic children in a two stimulus situation. J. Abnorm. Child Psychol., 2, 253-263 (1974).

RIMLAND, B. Infantile Autism. New York: Appleton-Century-Crofts (1964).

SCHOPLER, E. Visual versus tactile receptor preferences in normal and schizophrenic children. J. Abnorm. Psychol., 71, 108-114 (1966).

SCHREIBMAN, I. Effects of within-stimulus and extra-stimulus prompting on discrimination learning in autistic children. J. Appl. Behav. Analysis, 8, 91-112 (1975).

TUBBS, V. Types of linguistic disability in psychotic children. J. Appl. Behav. Analysis, 10, 232-240 (1966).

WALTERS, R., and Parke, R. The role of distance receptors in the development of social responsiveness. In L. P. Lipsitt and C. C. Spiker (eds.), Advances in Child Development and Behavior, 2, 59-96. New York: Academic Press (1965). 
WILHELM, H.; and Lovass, O. Stimulus overselectivity: a common feature in autism and mental retardation. Am. J. Ment. Def., $81,26-31$ (1976).

WING, J. Diagnosis, epidemiology, aetiology. In J. K. Wing (ed.), Childhood Autism: Clinical, Educational and Social Aspects. London: Pergamon Press (1966).

WING, L. Autistic Children: A Guide for Parents and Professionals. New Jersey: Citadel Press (1972). 
APPENDIX A

\section{CREAK'S (1963) DIAGNOSTIC CRITERIA}

1. Gross and sustained impairment of emotional relationships with people.

2. Apparent unawareness of his own personal identity to a degree inappropriate to his age.

3. Pathological preoccupation with particular objects or certain characteristics of them.

4. Sustained resistance to change in the environment and a striving to maintain or restore sameness.

5. Abnormal perceptual experience (in the absence of discernible organic abnormality).

6. Acute, excessive and seemingly illogical anxiety as a frequent phenomenon.

7. Speech either lost, or never acquired, or showing failure to develop beyond a level appropriate to an earlier age.

8. Distortion in motility patterns.

9. A background of serious retardation in which islets of normal, near normal or exceptional intellectual function or skill may appear. 


\section{APPENDIX B}

\section{AUTISTIC BEHAVIOR CHECKIIST O(KRUG, ARICK, ALMOND, 1978a)}

INSTRUCTIONS: Circle the number to indicate the items that most accurately describe the child.

Whirls self for long periods of time-

Learns a simple task but "forgets" quickly

Child frequently does not attend to social/environmental

stimuli

Does not follow simple commands which are given once (sit down, come here, stand up)

Does not use toys appropriately (spins tires, etc.) -

Poor use of visual discrimination when learning (fixates on one characteristic such as size, color or position-

Has no social smile-

Has pronoun reversal (you for $I$, etc.)

Insists on keeping certain objects with him/her

Seems not to hear, so that a hearing loss is suspected-

Speech is atonal and arhythmic

Rocks self for long periods of time-

Does not (or did not as a baby) reach out when reached for

Strong reactions to changes in routine/environment

Does not respond to own name when called out among two others (Joe, Bill, Mary)

Does a lot of lunging and darting about, interrupting with spinning, toe walking, flapping, etc.--

Not responsive to other people's facial expressions/ feelings

Seldom uses "yes" or "I"

Has "special abilities" in one area of development, which seems to rule out mental retardation-

Does not follow simple commands involving prepositions ("put the ball on the box" or "put the ball in the box")

Sometimes shows no "startle response" to a loud noise (may have thought child was deaf)

Slaps hands temper tantrums and/or frequent minor tantrums 
tively avoids eye contact

Resists being touched or held

Sometimes painful stimuli such as bruises, cuts

and injections evoke no reaction-

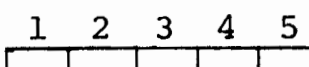

Is (or was as a baby) stiff and hard to hold

Is flaccid (doesn't cling) when held in arms Gets desired objects by gesturing

Walks on toes-

Hurts others by biting, hitting, kicking,

Repeats phrases over and over

Does not imitate other children at play

often will not blink when a bright light is

directed toward eyes----.----

Hurts self by banging head, biting hand, etc

Does not wait for needs to be met (wants things

immediately)

Cannot point to more than five named objects

Has not developed any friendships

Covers ears at many sounds

Twirls, spins and bangs objects a lot

Difficulties with toilet training

Uses 0-5 spontaneous words per day to communicate

wants and needs

often frightened or very anxious

Squints, frowns or covers eyes when in the presence

of natural light

Does not dress self without frequent help-

Repeats sounds or words over and over

"Looks through" people-

Echoes questions or statements made by

Frequently unaware of surroundings, and may be

oblivious to dangerous situations-

Prefers to manipulate and be occupied with

inanimate things

will feel, smell and/or taste objects in the environment-

Frequently has no visual reaction to a "new" person-_...---3

Gets involved in complicated "rituals" such as lining

things up, etc.

Is very destructive (toys and household items are soon broken)

A developmental delay was identified at or before 30 months of age-

Uses at least 15 but less than 30 spontaneous phrases

daily to communicate-

Stares into space for long periods of time

TOTAI 


\section{APPENDIX C}

A PROFILE OF THE SUBJECTS

Subject A:

Chronological age: 12-2

Autistic Behavior Checklist (ABC), 12/31/77: raw score 89

Sequenced Inventory of Communication Development (SICD), 2/8/78:

Receptive Communication Age (RCA): 40 months

Expressive Communication Age (ECA): 40 months

Test of Auditory Comprehension of Language (TACL), 1/15/78: raw score 63

Subject B:

Chronological age: 6-7

ABC, 10/4/78: raw score 114

Peabody Picture Vocabulary Test (PPVT), 9/13/78:

Form $B$, raw score 0

Alpern and Boll's Developmental Profile, 9/13/78:

physical age: $3-2$

self-help age: $3-0$

social age: 2-6

academic age: 2-4

communication age: 2-0

Subject C:

Chronological age: 7-1

$\underline{A B C}, 10 / 4 / 78$ : raw score 21

SICD, $9 / 20 / 78$ :

RCA: 48 months

ECA: 48 months

PPVT, 5/25/76: Form B, raw score 2.7; Form A, raw score 2.3 
Subject D:

Chronological age: 9-11

Alpern and Boll's Developmental Profile, 9/14/78:

$$
\begin{aligned}
& \text { physical age: } 2-8 \\
& \text { self-help age: } 3-4 \\
& \text { social age: : } 6-0 \\
& \text { academic age: } 1-10 \\
& \text { communication age: } 2-4
\end{aligned}
$$

PPVT, 9/14/78: Form B, raw score 12

receptive vocabulary age:, 2-2

TACL, 10/20/76: raw score 21

\section{Subject E:}

Chronological age: 6-1

$\underline{A B C}, 10 / 5 / 78: 73$

SICD, 9/19/78:

RCA: 16 months

ECA: 24 months

Alpern and Boll's Developmental Profile, 3/31/77:

physical age : $1-8$

self-help age: $1-8$

social age: 10 months

academic age: 1-0

communication age: $1-2$

PPVT, 9/14/78: Form A, raw score 1

\section{Subject F:}

Chronological Age: 9-5

ABC, 10/16/78: 91

Leiter International Performance Scale (LIPS), 9/20/78:

all items correct at $4 \mathrm{yr}$. level

one item correct at 5, 6 and $7 \mathrm{yr}$. levels

operates cognitively at $5 \mathrm{yr}$. level

PPVT, 10/16/78: Form B, Raw Score 8 
Subject G:

Chronological age: 10-3

$\underline{\mathrm{ABC}}, 10 / 4 / 78: 84$

LIPS, August $/ 78$

age level approximately 21 months

SICD, 10/25/77:

RCA: 24 months

ECA: 28 months

PPVT, 5/11/77: Form A, raw score 17

receptive vocabulary age: $2-4$

Alpern and Boll's Developmental Profile, 9/21/77:

physical age: 3-2

self-help age: 4-4

social age: 2-10

academic age: $2-6$

communication age: $2-6$

TACL, May/77: raw score 7

\section{Subject $\mathrm{H}$ :}

Chronological age: 15-9

$\underline{A B C}$, Fall $/ 77: 80.5$

PPVT, 4/26/77: Form A and B, raw score 0

SICD, 10/25/77:

$\mathrm{RCA}$ : 12 months

ECA: 16 months

Alpern and Boll's Developmental Profile, 9/22/77:

physical age: $5-4$

self-help age: 5-4

social age: 2-0

academic age: 1-3

communication age: $1-4$ 
APPENDIX D

\section{SUBJECT'S RAW SCORES (SECONDS)}

\begin{tabular}{|c|c|c|c|c|c|c|c|c|}
\hline \multirow{3}{*}{$\begin{array}{l}\text { No Sd } \\
A+V\end{array}$} & 1 & 2 & 3 & 4 & 5 & 6 & 7 & 8 \\
\hline & 1.0 & 1.0 & 1.0 & .5 & 1.0 & 1.1 & 1.0 & 1.0 \\
\hline & 1.0 & 1.0 & 1.0 & 1.1 & .9 & 1.0 & 1.0 & 1.2 \\
\hline . & 1.2 & 1.2 & 1.1 & 1.1 & 1.1 & 1.1 & 1.2 & 1.2 \\
\hline V & 110.0 & 2.5 & 2.0 & 2.0 & 2.5 & 2.0 & 1.5 & 1.6 \\
\hline$+v$ & 1.5 & 1.4 & 1.0 & 1.5 & 1.5 & 5.0 & 2.0 & 1.5 \\
\hline sd & 72.0 & 3.0 & 2.5 & 1.5 & 2.0 & 1.0 & 1.0 & 1.0 \\
\hline
\end{tabular}

Subject $A$

Test Day 1

No Sd

$A+V$

A

$\mathrm{V}$

$A+V$

No $S d$

\begin{tabular}{|r|r|r|r|r|r|r|r|}
\hline 1 & 2 & 3 & 4 & 5 & 6 & \multicolumn{1}{c|}{4} \\
\hline 6.0 & 1.5 & 1.0 & 1.0 & .5 & .5 & .5 & .5 \\
\hline 1.5 & 1.4 & 1.6 & 1.0 & 1.0 & 1.2 & 1.0 & 1.2 \\
\hline 1.6 & 1.1 & 1.2 & 3.0 & 1.0 & 1.0 & 1.0 & 1.0 \\
\hline 178.0 & 1.1 & 1.0 & 1.6 & 1.2 & 1.2 & 1.1 & 1.3 \\
\hline 1.0 & 1.0 & 1.5 & 1.0 & 1.6 & 1.0 & .5 & 1.5 \\
\hline & & \multicolumn{1}{|c|}{ EXTINGUTSHED } & & & \\
\hline
\end{tabular}

Subject A

Test Day 2

No $s a$

$\mathrm{A}+\mathrm{V}$

$\mathrm{V}$

A

$A+V$

No $S d$

\begin{tabular}{|c|c|c|c|c|c|c|c|}
\hline 1 & 2 & 3 & 4 & 5 & 6 & 7 & 8 \\
\hline & & & & & & & \\
\hline 1.1 & 1.5 & 1.2 & 1.5 & 1.5 & 1.0 & 2.0 & 2.5 \\
\hline 1.5 & 1.0 & 1.0 & 2.5 & 1.5 & 1.5 & 1.9 & 1.4 \\
\hline 1.2 & 1.4 & 1.3 & 1.1 & 1.4 & 1.2 & 1.4 & 1.0 \\
\hline 1.4 & 1.5 & 1.0 & 1.0 & 1.4 & 1.3 & 1.5 & 1.0 \\
\hline 9.5 & 2.5 & 2.0 & 2.0 & 1.5 & 9.5 & 1.5 & 1.5 \\
\hline
\end{tabular}

Subject B

Test Day 1

No Sd

$\mathrm{A}+\mathrm{V}$

$\mathrm{V}$.

A

$A+V$

No Sd

\begin{tabular}{|c|c|c|c|c|c|c|c|}
\hline 1 & 2 & 3 & 4 & 5 & 6 & 7 \\
\hline 1.5 & 1.2 & 1.1 & 1.2 & 1.2 & 1.4 & 1.1 & 1.0 \\
\hline 6.0 & 1.1 & 1.6 & 2.2 & 1.1 & 1.0 & 1.5 & 2.0 \\
\hline 1.4 & 1.2 & 1.4 & 1.2 & 1.2 & 1.0 & 1.0 & 1.0 \\
\hline 1.2 & 1.4 & 1.5 & 1.5 & 1.1 & 1.1 & 2.2 & .6 \\
\hline 100.0 & 3.0 & 6.5 & & EXTINGUIS & \\
\hline
\end{tabular}

Subject B

Test Day 2 


\begin{tabular}{|c|c|c|c|c|c|c|c|c|}
\hline & 1 & 2 & 3 & 4 & 5 & 6 & 7 & 8 \\
\hline No Sd & 10.0 & 3.0 & 2.0 & 1.5 & 1.0 & 2.2 & 3.5 & 1.0 \\
\hline$A+V$ & 1.0 & .5 & .5 & 1.0 & 1.0 & 1.0 & 1.0 & 3.0 \\
\hline A & 2.5 & .6 & 3.0 & 2.0 & .8 & 2.1 & 1.5 & 3.8 \\
\hline $\mathrm{V}$ & 1.9 & 2.6 & 4.5 & 1.9 & 1.5 & 2.0 & 2.5 & 1.1 \\
\hline$A+V$ & 2.5 & 2.1 & 1.1 & 1.2 & 1.4 & 2.0 & .6 & 3.0 \\
\hline No Sd & 179.0 & & & \multicolumn{3}{|c|}{ EXTINGUISHED } & & \\
\hline
\end{tabular}

Subject $C$ Test Day 1

No Sa

$\mathrm{A}+\mathrm{V}$

$A$

$\mathrm{V}$

$\mathrm{A}+\mathrm{V}$

No Sd

\begin{tabular}{|c|c|c|c|c|c|c|c|}
\hline 1 & 2 & 3 & 4 & 5 & 6 & 7 & 8 \\
\hline 8.0 & 3.5 & 6.6 & 1.5 & 2.5 & 1.9 & 1.0 & 1.0 \\
\hline 1.1 & .9 & .9 & 1.0 & 1.5 & 1.1 & 1.2 & 1.0 \\
\hline 1.0 & 1.5 & 1.0 & 1.4 & 1.5 & 1.1 & 1.0 & 1.0 \\
\hline 1.4 & 1.5 & 1.0 & 2.2 & 1.6 & 1.8 & 2.0 & 1.4 \\
\hline .6 & 1.3 & .7 & 1.0 & .6 & 1.0 & 1.0 & 1.0 \\
\hline & & & EXTINGUISHED & & & \\
\hline
\end{tabular}

Subject $C$

Test Day 2

No $S d$

$\mathrm{A}+\mathrm{V}$

A

$\mathrm{V}$

$\mathrm{A}+\mathrm{V}$

No Sd

\begin{tabular}{|c|c|c|c|c|c|c|c|}
\hline 1 & 2 & 3 & \multicolumn{1}{c}{4} & \multicolumn{1}{c|}{6} & \multicolumn{1}{c|}{7} & 8 \\
\hline 2.0 & 1.5 & .5 & 5.2 & .5 & .5 & 2.0 & 2.5 \\
\hline 2.5 & 2.0 & 3.2 & 2.2 & 3.1 & 1.1 & 2.9 & 1.0 \\
\hline 1.0 & 2.2 & 2.5 & 2.0 & 2.1 & .5 & 11.1 & 3.5 \\
\hline .5 & 1.5 & 2.5 & 1.5 & 1.4 & 1.2 & 6.5 & .5 \\
\hline 1.6 & 1.2 & 1.2 & 1.0 & 1.2 & 1.0 & 1.5 & 1.5 \\
\hline 1.5 & 2.6 & 7.0 & 5.0 & 2.0 & 5.0 & 13.5 & 3.2 \\
\hline
\end{tabular}

Subject D

Test Day 1

No sa

$\mathrm{A}+\mathrm{V}$

A

V

$\mathrm{A}+\mathrm{V}$

No $S d$

\begin{tabular}{|c|c|c|c|c|c|c|c|}
\hline 1 & 2 & 3 & 4 & 5 & 6 & 7 & 8 \\
\hline 1.0 & 2.0 & 3.0 & 3.0 & 1.5 & 5.5 & .5 & 1.5 \\
\hline 1.2 & 1.0 & 1.5 & 1.0 & 1.5 & 1.5 & 1.0 & 1.0 \\
\hline .5 & 1.2 & 1.0 & .6 & 1.0 & 1.5 & 2.0 & 1.5 \\
\hline 1.1 & 3.4 & 1.0 & 1.1 & 1.1 & 1.0 & 1.0 & .9 \\
\hline 2.1 & 1.0 & 1.0 & 1.1 & 1.2 & 1.1 & 1.1 & 1.0 \\
\hline 3.2 & 7.6 & 1.0 & 3.5 & 3.0 & 3.0 & 5.2 & 3.5 \\
\hline
\end{tabular}

Subject D

Test Day 2 


\begin{tabular}{|c|c|c|c|c|c|c|c|c|c|}
\hline \multirow{7}{*}{$\begin{array}{l}\text { No Sd } \\
A+V \\
V \\
A \\
A+V \\
\text { No Sd }\end{array}$} & 1 & 2 & 3 & 4 & 5 & 6 & 7 & 8 & \\
\hline & 4.7 & 4.2 & 2.0 & 2.0 & 5.2 & 2.0 & 2.2 & 2.2 & \multirow{6}{*}{$\begin{array}{l}\text { Subject } \mathrm{E} \\
\text { Test Day } 1\end{array}$} \\
\hline & 1.5 & 1.5 & 1.5 & 1.2 & 1.0 & 1.2 & 1.5 & 1.2 & \\
\hline & 1.0 & 1.9 & 2.5 & 1.5 & 1.9 & 3.5 & 2.0 & 1.5 & \\
\hline & 7.5 & 2.7 & 1.5 & 1.9 & 3.0 & 1.9 & 2.9 & 4.0 & \\
\hline & 2.0 & 1.5 & 1.1 & 1.9 & 1.2 & 1.3 & 5.9 & 1.5 & \\
\hline & 26.0 & 2.0 & 8.0 & 2.0 & 2.0 & 100.0 & 3.0 & 7.5 & \\
\hline
\end{tabular}

\begin{tabular}{|c|c|c|c|c|c|c|c|c|c|}
\hline \multirow{7}{*}{$\begin{array}{l}\text { No Sd } \\
A+V \\
V \\
A \\
A+V \\
\text { No Sd }\end{array}$} & 1 & 2 & 3 & 4 & 5 & 6 & 7 & 8 & \\
\hline & 5.0 & 1.2 & 3.0 & 6.9 & 2.0 & 3.5 & 2.0 & 8.0 & \multirow{6}{*}{$\begin{array}{l}\text { Subject E } \\
\text { Test Day }\end{array}$} \\
\hline & 4.0 & 1.5 & 1.1 & 1.1 & 1.1 & 1.2 & 1.2 & 1.0 & \\
\hline & 1.2 & 1.0 & 1.0 & 1.5 & 2.0 & 1.2 & 1.1 & 1.0 & \\
\hline & 1.6 & 1.6 & 1.0 & 1.2 & 1.4 & 1.0 & 1.0 & 1.2 & \\
\hline & .5 & 1.1 & 1.0 & 1.0 & 1.2 & 1.0 & 1.1 & 1.0 & \\
\hline & 2.0 & 103.0 & 9.5 & 152.0 & 2.0 & 2.0 & 1.0 & 74.0 & \\
\hline
\end{tabular}

\begin{tabular}{|c|c|c|c|c|c|c|c|c|c|}
\hline & 1 & 2 & 3 & 4 & 5 & 6 & 7 & 8 & \multirow{7}{*}{$\begin{array}{l}\text { Subject F } \\
\text { Test Day } 1\end{array}$} \\
\hline & 1.5 & 1.0 & 1.0 & 3.0 & 1.5 & .5 & .5 & 1.5 & \\
\hline & 1.0 & .5 & .5 & 1.0 & .9 & .9 & .9 & 1.0 & \\
\hline & 1.4 & 1.0 & .6 & .6 & .9 & 1.0 & 1.2 & 1.0 & \\
\hline \multirow{3}{*}{$\begin{array}{l}\text { No Sd } \\
A+V \\
V \\
A \\
A+V \\
\text { No } S d\end{array}$} & 1.5 & 1.0 & 1.0 & 1.2 & 1.0 & 1.0 & 1.0 & 1.0 & \\
\hline & .6 & .9 & .9 & 1.0 & 1.0 & 1.0 & .9 & 1.0 & \\
\hline & 109.0 & 6.5 & 8.9 & 10.9 & 7.5 & 9.8 & 8.4 & 5.5 & \\
\hline
\end{tabular}

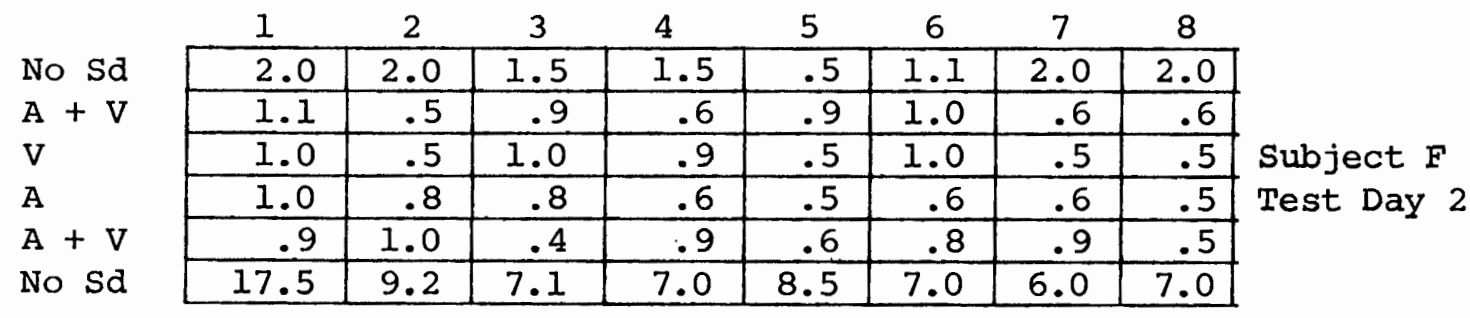




\begin{tabular}{|c|c|c|c|c|c|c|c|c|c|}
\hline \multirow{7}{*}{$\begin{array}{l}\text { No Sd } \\
A+V \\
A \\
V \\
A+V \\
\text { No Sd }\end{array}$} & 1 & 2 & 3 & 4 & 5 & 6 & 7 & 8 & \multirow{7}{*}{$\begin{array}{l}\text { Subject G } \\
\text { Test Day } 1\end{array}$} \\
\hline & 3.0 & 7.9 & 4.5 & 12.0 & 4.1 & 4.0 & 5.1 & 9.5 & \\
\hline & 2.4 & 1.8 & 2.5 & 1.8 & .7 & 1.0 & 1.6 & 1.2 & \\
\hline & 1.2 & 2.0 & 6.2 & 1.5 & 2.2 & 2.9 & 2.4 & 2.1 & \\
\hline & 3.0 & 2.1 & 2.2 & 2.0 & 2.0 & 2.1 & 2.4 & 2.1 & \\
\hline & 1.5 & 1.5 & 1.8 & 2.0 & 1.9 & 2.5 & 1.9 & 1.9 & \\
\hline & 94.0 & 2.0 & 2.0 & 10.5 & 24.0 & 7.0 & 4.5 & 15.2 & \\
\hline
\end{tabular}

\begin{tabular}{|c|c|c|c|c|c|c|c|c|c|}
\hline & 1 & 2 & 3 & 4 & 5 & 6 & 7 & 8 & \multirow{7}{*}{$\begin{array}{l}\text { Subject G } \\
\text { Test Day } 2\end{array}$} \\
\hline No $S d$ & 6.0 & 2.5 & 2.5 & 3.5 & 5.2 & 2.5 & 9.5 & 3.0 & \\
\hline$A+V$ & 1.5 & 2.1 & 3.0 & 1.1 & 2.0 & 1.8 & 1.5 & 1.5 & \\
\hline A & 3.0 & 1.5 & 3.0 & 1.6 & 2.6 & 2.0 & 1.6 & 3.0 & \\
\hline V & 1.5 & 2.0 & 1.5 & 2.5 & 1.5 & 1.5 & 1.4 & 1.0 & \\
\hline$A+V$ & 1.4 & 1.5 & 2.0 & 2.0 & 2.0 & 1.5 & 1.5 & 1.4 & \\
\hline No Sd & 8.0 & 13.2 & 2.5 & 15.2 & 1.2 & 5.0 & 8.5 & 2.9 & \\
\hline
\end{tabular}

\begin{tabular}{|c|c|c|c|c|c|c|c|c|c|}
\hline \multirow{4}{*}{$\begin{array}{l}\text { No Sd } \\
A+V \\
V\end{array}$} & 1 & 2 & 3 & 4 & 5 & 6 & 7 & 8 & \multirow{7}{*}{$\begin{array}{l}\text { Subject } \mathrm{H} \\
\text { Test Day } 1\end{array}$} \\
\hline & 6.0 & 3.0 & 2.0 & 3.0 & \multicolumn{3}{|c|}{ E\$TINGUISHED } & & \\
\hline & 1.0 & 13.0 & 1.0 & 6.5 & 87.0 & 1.5 & 2.0 & EXT. & \\
\hline & 1.6 & 1.5 & 1.5 & 2.0 & 5.0 & 4.5 & 1.6 & 4.5 & \\
\hline & 4.5 & 2.5 & 13.0 & 1.0 & 1.5 & 13.0 & 4.5 & 2.0 & \\
\hline$A+V$ & 79.0 & 1.0 & 1.0 & 1.0 & 6.9 & 1.0 & 1.0 & 1.0 & \\
\hline No $\mathrm{sd}$ & 2.5 & 7.5 & 11.0 & 4.5 & 1.0 & 1.0 & 1.0 & 11.0 & \\
\hline
\end{tabular}

\begin{tabular}{|c|c|c|c|c|c|c|c|c|c|}
\hline \multirow{4}{*}{$\begin{array}{l}\text { No Sd } \\
A+V \\
V\end{array}$} & 1 & 2 & 3 & 4 & 5 & 6 & 7 & 8 & \\
\hline & 2.0 & 2.0 & 1.0 & 1.5 & 1.5 & 2.0 & 1.0 & 2.0 & \multirow{6}{*}{$\begin{array}{l}\text { Subject } \mathrm{H} \\
\text { Test Day } 2\end{array}$} \\
\hline & 1.2 & 1.2 & .5 & 1.0 & .5 & 1.0 & .5 & 1.0 & \\
\hline & 1.0 & & & \multicolumn{3}{|c|}{ EXTIWGUISHED } & & & \\
\hline A & 1.5 & 1.0 & .5 & 1.9 & 1.2 & .9 & 1.1 & 1.0 & \\
\hline$A+V$ & 1.0 & 1.0 & 1.0 & 1.1 & 1.0 & 1.2 & 1.5 & 1.4 & \\
\hline No Sd & & & & STING & HED & & & & \\
\hline
\end{tabular}


APPENDIX E

CONVERSION OF RAW SCORES IN SECONDS TO Z-SCORES 

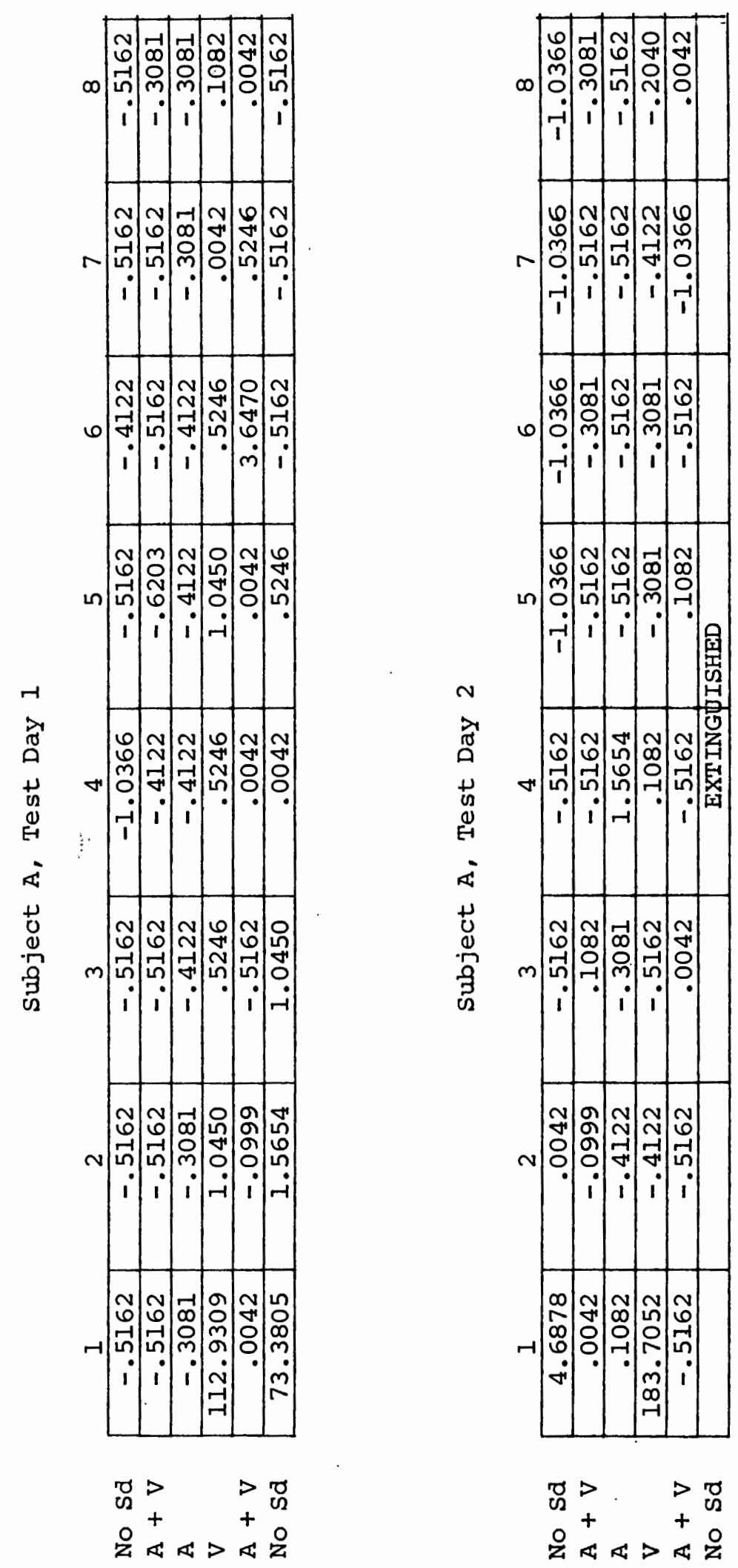

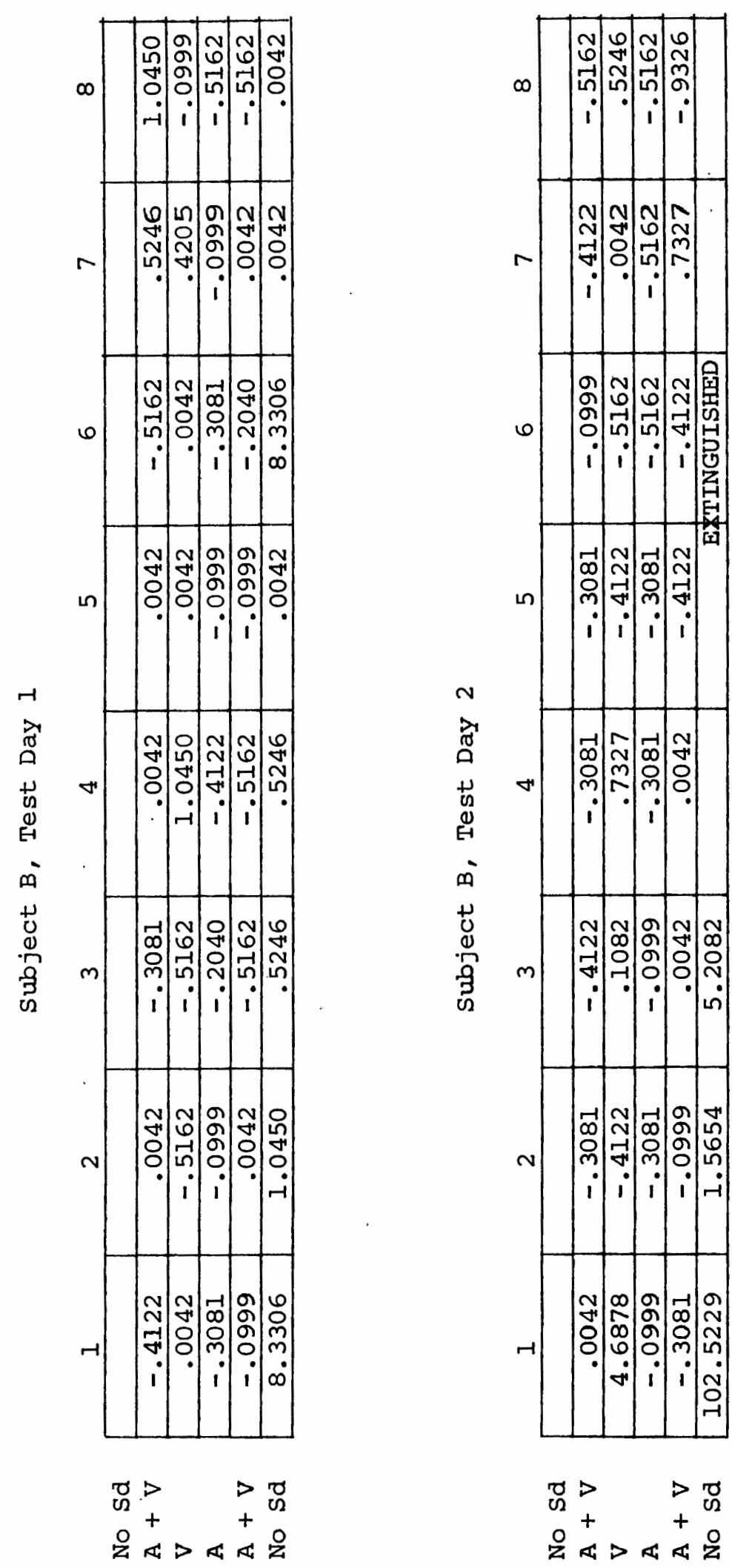

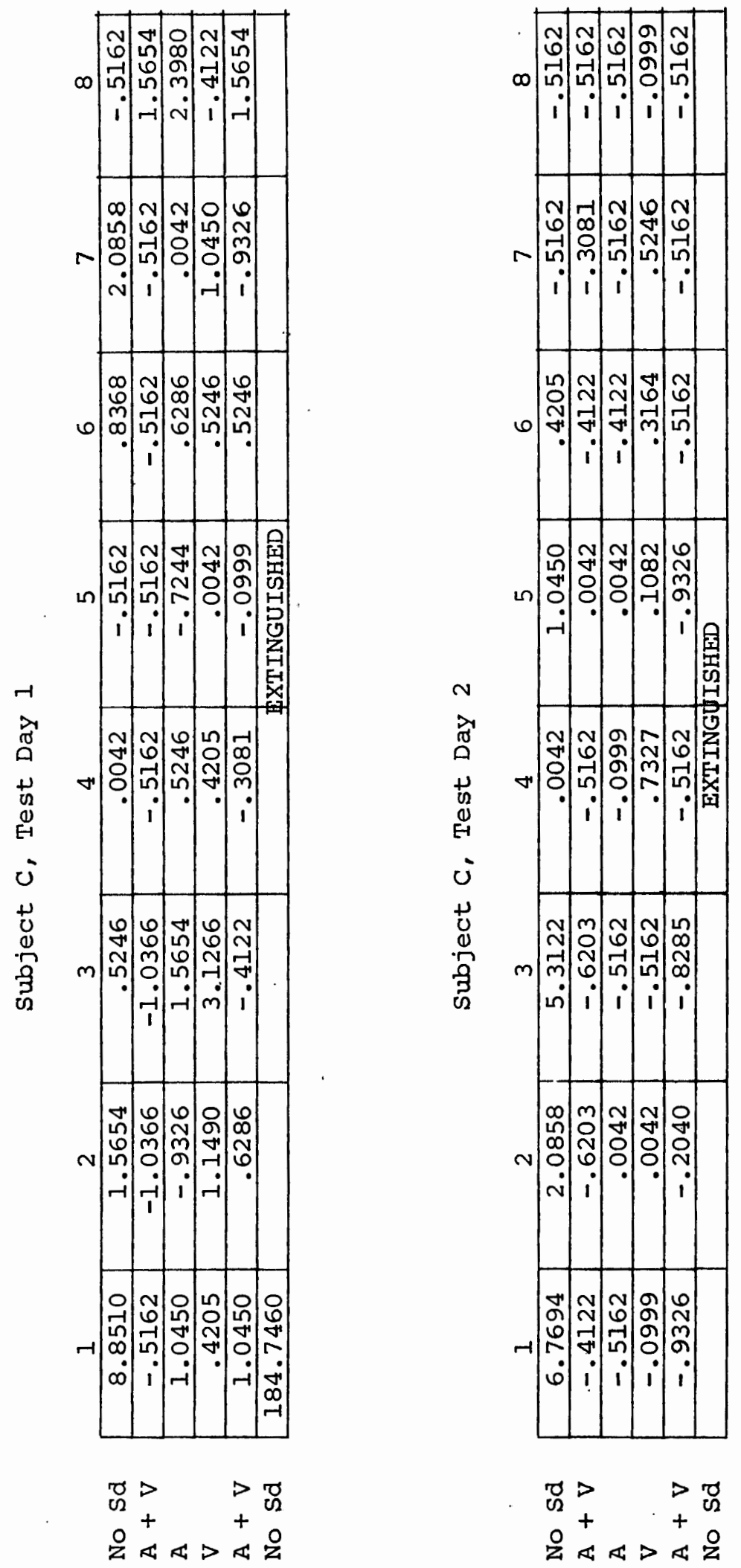

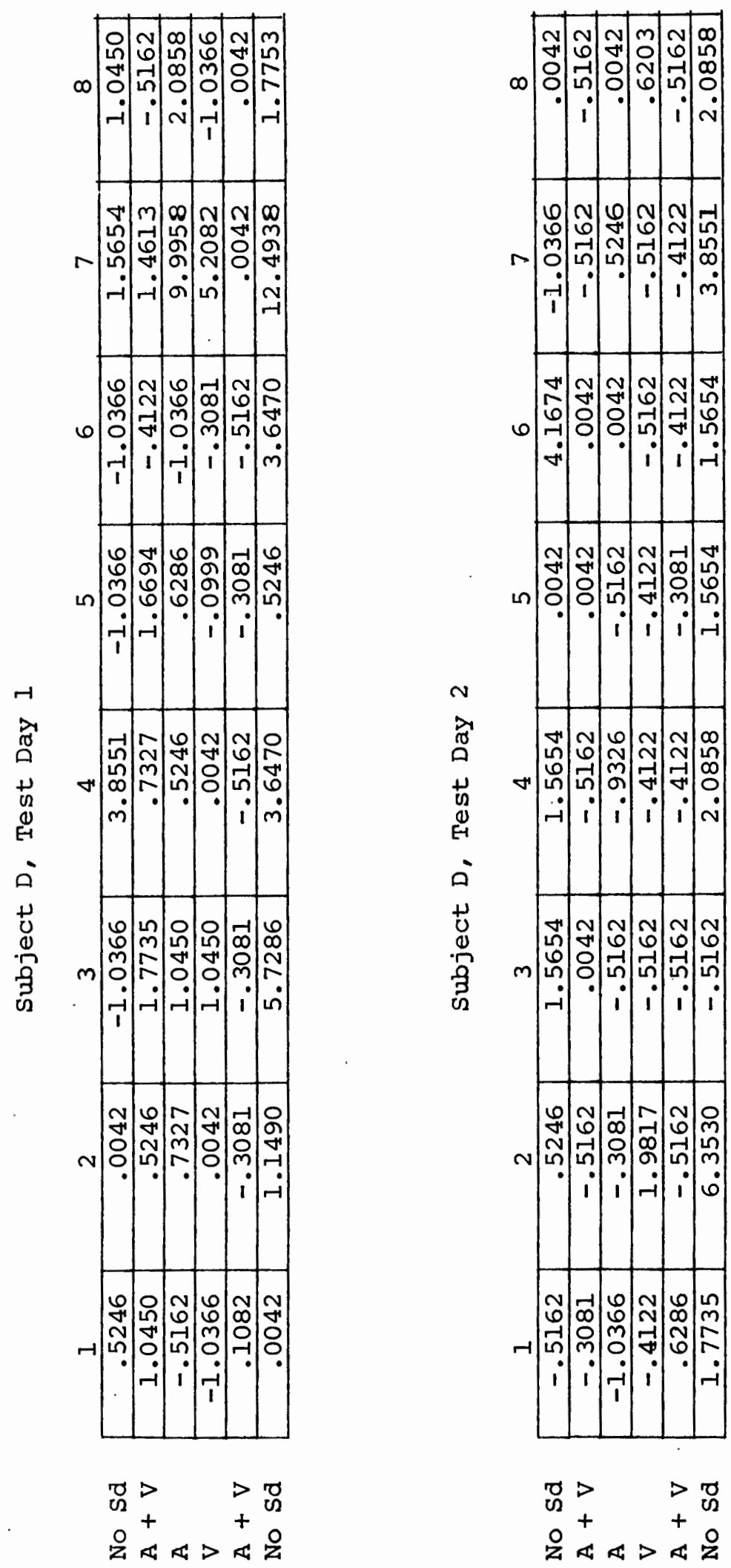

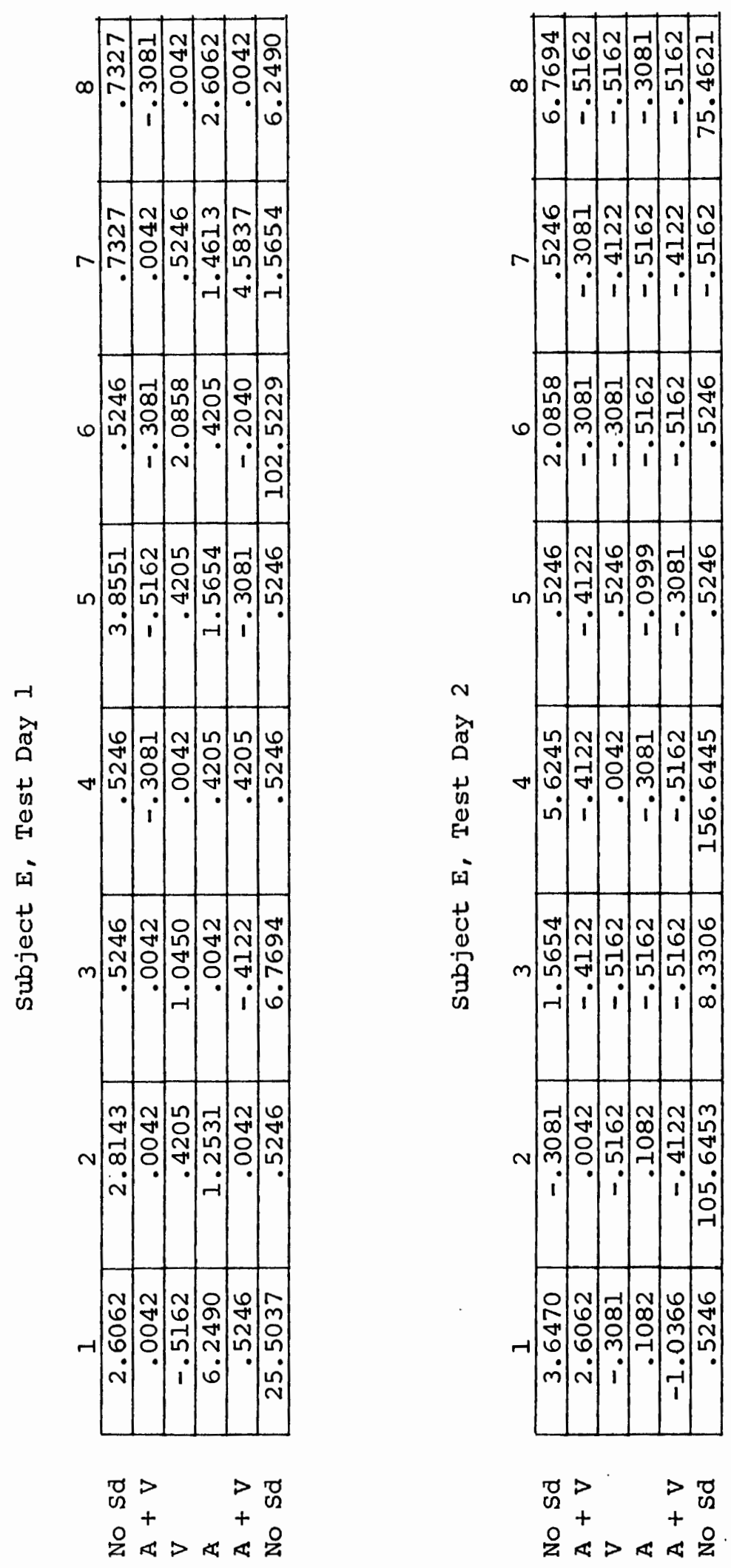

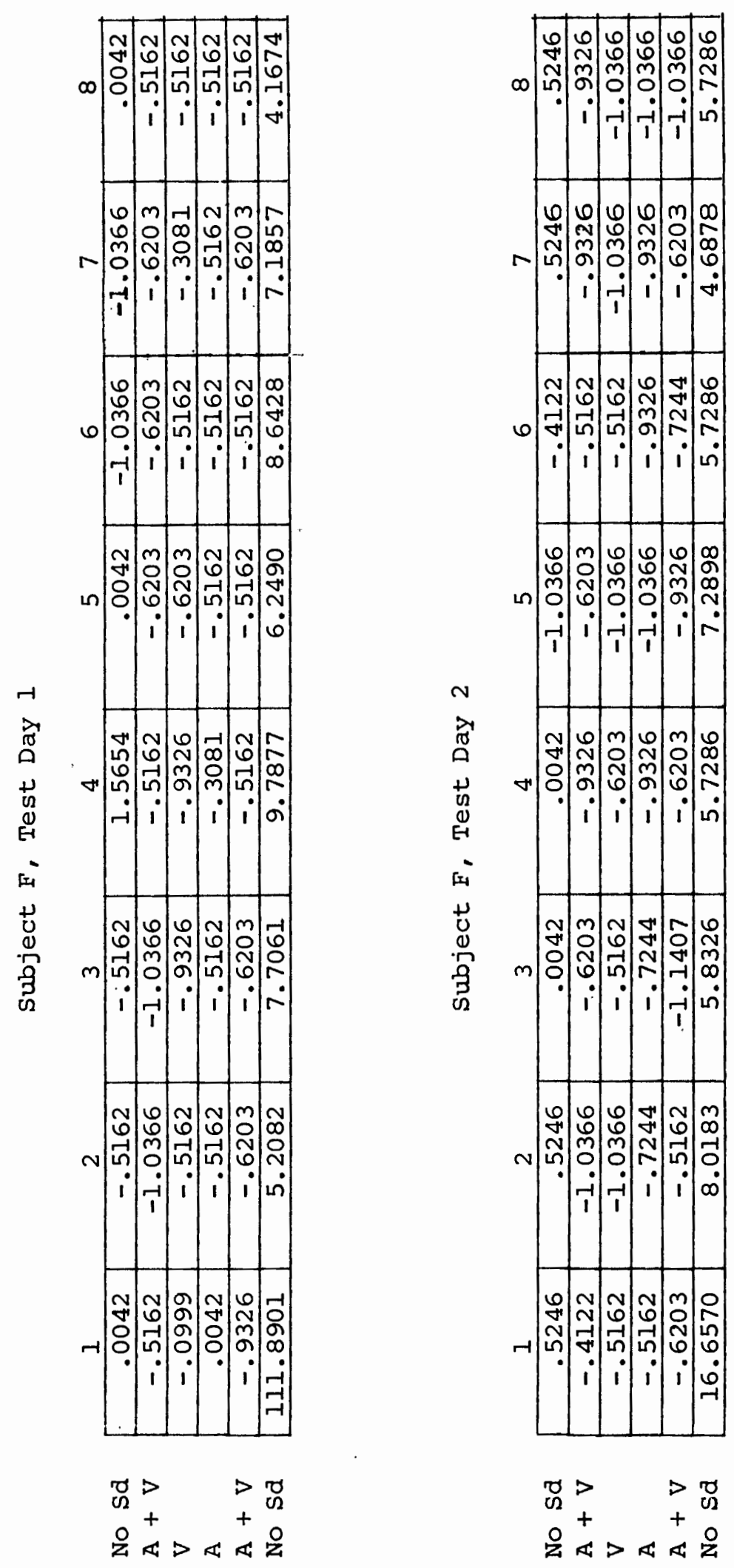

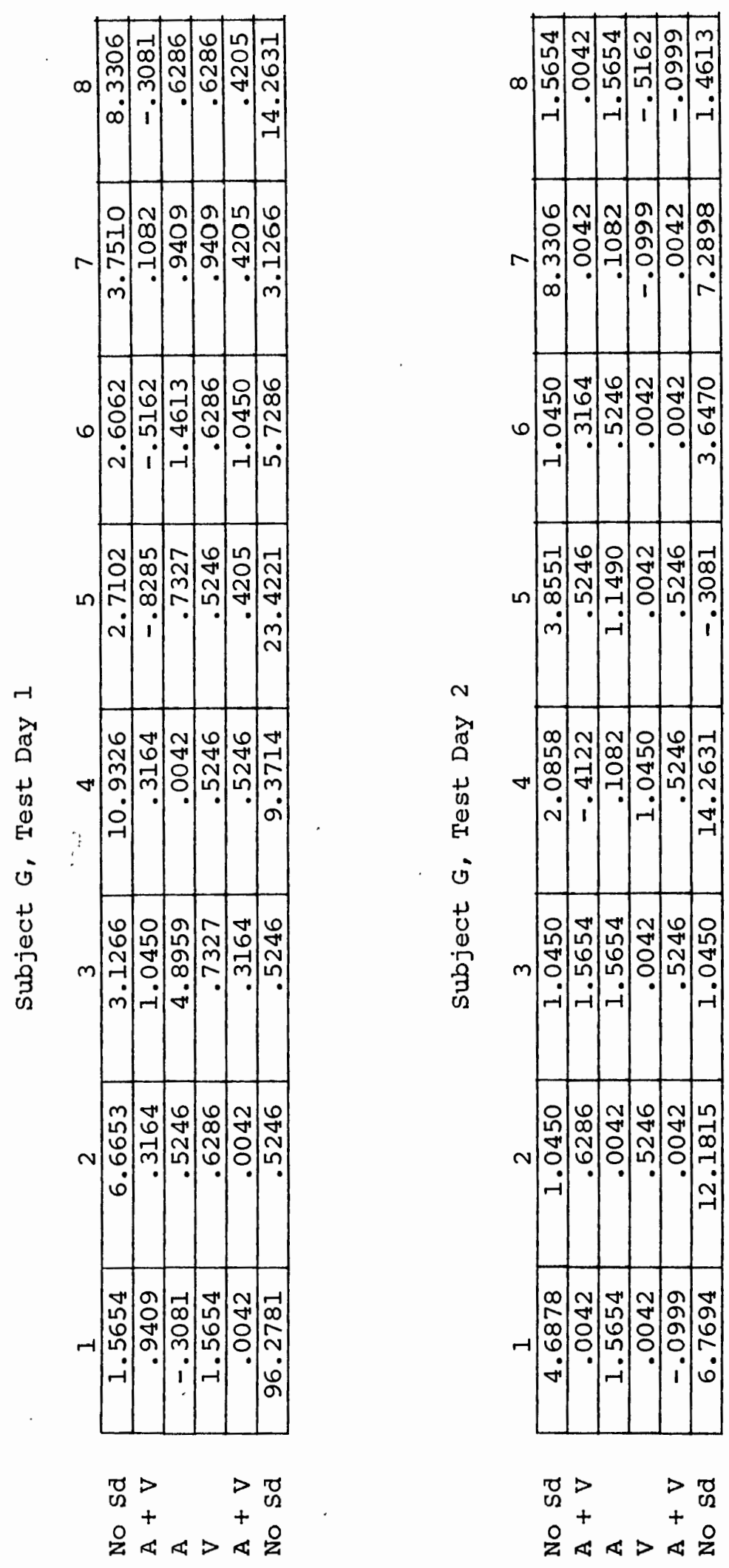

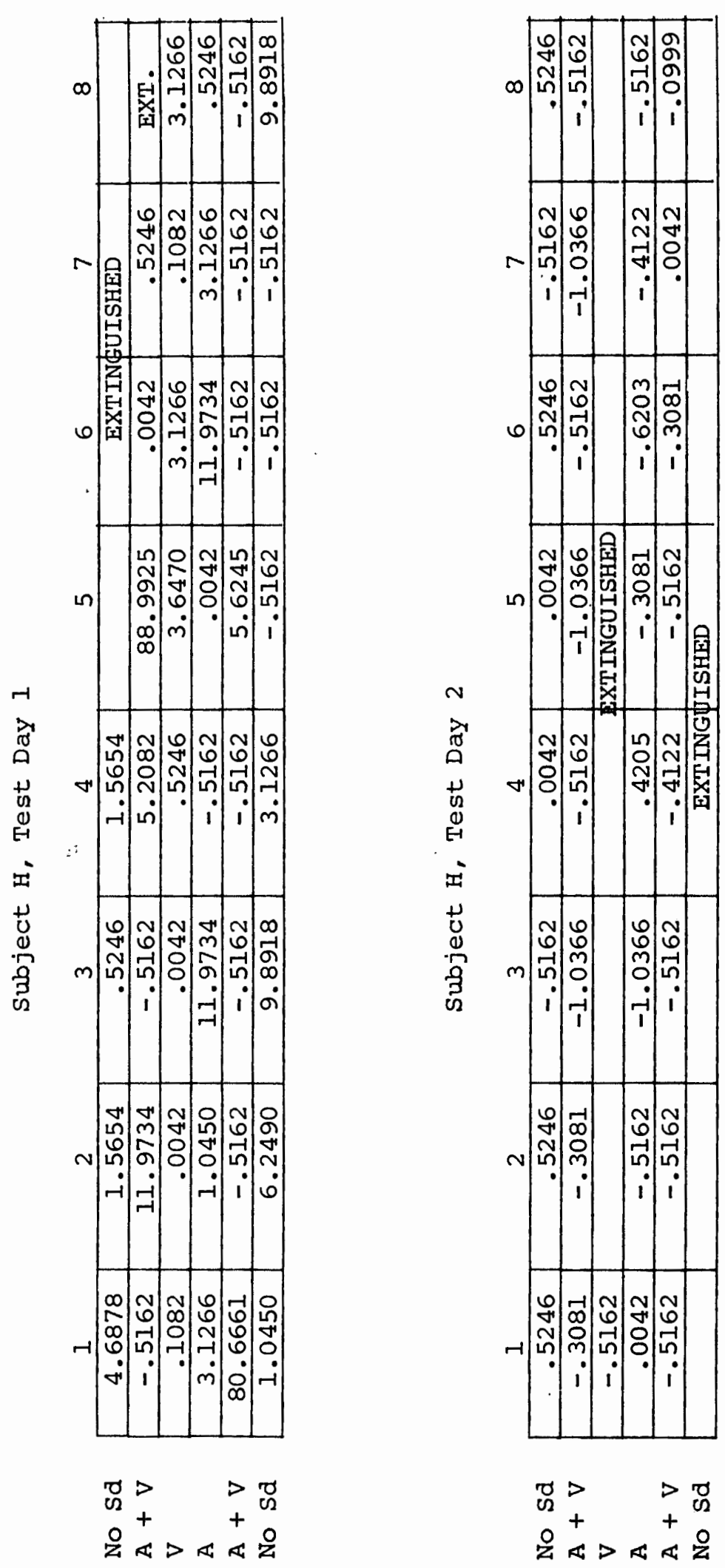